\title{
ANÁLISE GEOAMBIENTAL APLICADA À BACIA HIDROGRÁFICA DO RIBEIRÃO DE POÇOS, POÇOS DE CALDAS (MG)
}

\author{
Fábio Albers Justino ${ }^{1}$ \\ Diego de Souza Sardinha ${ }^{2}$
}

Resumo: O presente trabalho realizou a análise geoambiental do Ribeirão de Poços em Poços de Caldas (MG). A rede de drenagem é de $20,05 \mathrm{~km}$ com uma densidade de drenagem de $1,67 \mathrm{~km} / \mathrm{km}^{2}$. O córrego do Parque é o que apresenta maiores mudanças quanto à geometria, as larguras variam de $3,67 \mathrm{~m}$ a $2,35 \mathrm{~m}$, enquanto $\mathrm{a}$ profundidade de $0,21 \mathrm{~m}$ a $0,03 \mathrm{~m}$. Os parâmetros de qualidade da água se elevam após a área urbana, assim como a vazão. Ao contrário das concentrações de oxigênio dissolvido onde os valores, na maioria dos pontos amostrados, encontramse abaixo do permitido pela legislação vigente de $5,0 \mathrm{mg} / \mathrm{L}$. A quantidade de sólidos totais dissolvidos e suspensos removidos anualmente correspondem a 7357,27 t/ano. Com isso, sugere-se um plano efetivo de controle, monitoramento e fiscalização ambiental para a bacia estudada.

Palavras-chave: Caracterização Fisiográfica; Geomorfologia Fluvial: Transporte de Sedimentos.

\section{GEOENVIRONMENTAL ANALYSIS APPLIED TO POÇOS STREAM WATERSHED, POÇOS DE CALDAS (MG)}

Abstract: The present study assessed the Poços stream geoenvironmental analysis in Poços de Caldas (MG). The drainage network is $20.05 \mathrm{~km}$ with a drainage density of $1.67 \mathrm{~km} / \mathrm{km}^{2}$. The Parque stream is the one that presents most changes as far as geometry, with widths varying from $3,67 \mathrm{~m}$ to $2,35 \mathrm{~m}$, and depth from $0,21 \mathrm{~m}$ to 0,03 $\mathrm{m}$. The water quality parameters rise past the urban area, as well as the flow. Unlike the dissolved oxygen concentrations whose values, in most of the sampled points, are below the one allowed by the current legislation of $5.0 \mathrm{mg} / \mathrm{L}$. The amount of total dissolved and suspended solids annually removed corresponds to 7357.27 t/year. Therefore, an effective control, monitoring and environmental inspection plan for the studied basin is suggested.

Keywords: Physiographic Characterization; Fluvial Geomorphology; Sediment transport.

\footnotetext{
${ }^{1}$ Graduando em Ciência e Tecnologia pela Universidade Federal de Alfenas (UNIFAL). fabioalbersjustino@gmail.com

${ }^{2}$ Professor Adjunto da Universidade Federal de Alfenas (UNIFAL) diegosouzasardinha@gmail.com

Estudos Geográficos, Rio Claro, 17(1): 68-90, jan./jun. $2019 \quad$ (ISSN 1678-698X) http://www.periodicos.rc.biblioteca.unesp.br/index.php/estgeo
} 


\section{INTRODUÇÃO E OBJETIVO}

O município de Poços de Caldas teve um grande incremento demográfico e consequente ocupação do meio físico entre os anos de 1960 a 1990 (177\%), com um grau de urbanização de 94\% (PMPC, 2006, p.19-20). Segundo a PMPC (2006, p. 23), em 2000, o censo demográfico apontou uma população total 135.567 habitantes, dos quais apenas 3,5\% residiam na área rural (4.803 habitantes). Os dados referentes ao censo demográfico de 2010 indicam uma população total de 152.435 habitantes, sendo 3.713 habitantes residentes na área rural $(2,4 \%)$ e 148.722 habitantes na área urbana $(97,6 \%)$ com uma densidade demográfica de 278,54 hab./km² (IBGE, 2018).

O processo de urbanização da cidade de Poços de Caldas provocou transformações intensas na paisagem. Os núcleos urbanos comumente originaramse próximos a setores de relevo menos acentuado e ao longo de corpos d'água. Esta ocupação sem o planejamento adequado desencadeou e acelerou diversos problemas socioambientais, tais como a degradação da qualidade das águas, assoreamentos, inundações e enchentes, gerando impactos negativos e degradação ambiental sobre os recursos hídricos superficiais do município.

Atualmente, há grande preocupação em se ter uma abordagem integrada para estudos em bacias hidrográficas urbanas (Fujimoto, 2002; Souza e Tundisi, 2003; Carvalho, 2005; Lucas e Cunha, 2007; Almeida, 2009; Menezes et al., 2010; Oliveira e Campos, 2012; Machado e Dupas, 2013; Chuerubim e Pavanin, 2013; Vitte e Mello, 2013; Carvalho et al., 2015; Costa et al., 2018; Oliveira et al., 2018). Estes locais apresentam uma ampla gama de problemas geoambientais, provocados principalmente pela ocupação desordenada da terra, despejos de efluentes domésticos e industriais, retificação das calhas dos rios, erosão, etc., que por sua vez, ocasionam a modificação da paisagem e conseqüente degradação da qualidade da água.

A região central de Poços de Caldas (MG) se enquadra neste cenário, pois possui densa e crescente urbanização com uso da terra associada à falta de planejamento, gerando impactos no rio que drena a área urbana do município, no caso o Ribeirão de Poços. Assim, este trabalho tem como objetivo a análise geoambiental do Ribeirão de Poços, área urbana de Poços de Caldas (MG), auxiliando no conhecimento dos geossistemas e fornecendo importantes subsídios para seu desenvolvimento sustentável.

\section{MATERIAIS E MÉTODOS}

$\mathrm{Na}$ primeira etapa foi realizado um inventário preliminar baseado em pesquisas bibliográficas e pesquisas em arquivos de órgãos ambientais, técnicos e científicos. A partir da carta: SP-23-V-C-VI-4 (IBGE, 1972) foi elaborado o mapa de delimitação e localização da bacia do Ribeirão de Poços, juntamente com a imagem Digital Globe do aplicativo Google Earth Pro (2018), adequando os dados para o Sistema de Coordenadas Universal Transversa de Mercator (UTM), Datum horizontal WGS84 - Zona 23S.

O perfil longitudinal foi calculado a partir dos dados de altitude em relação à distância do inicio do Ribeirão de Poços até seu exutório, Equação (1) conforme Cunha (2017, p. 181).

$$
H=f(L)
$$

Estudos Geográficos, Rio Claro, 17(1): 68-90, jan./jun. 2019 (ISSN 1678-698X) http://www.periodicos.rc.biblioteca.unesp.br/index.php/estgeo 
Onde: $\mathrm{H}$ = altitude $(\mathrm{m}) ;(\mathrm{L})=$ distância do canal principal $(\mathrm{m})$.

A sinuosidade do curso d'água principal foi calculada através da relação entre a distância do exutório e o início do Ribeirão de Poços em linha reta, e o comprimento do rio principal, conforme Equação (2) conforme Cunha (2017, p.159).

$$
I s=\frac{L}{L_{r}}
$$

Onde: Is = índice de sinuosidade; $L=$ comprimento do rio principal $(k m) ; L_{r}=$ comprimento, em linha reta, do exutório até a nascente mais distante $(\mathrm{km})$.

A rede de drenagem e/ou conjunto de todos os cursos d'água da bacia do Ribeirão de Poços foi calculada através da Equação (3) conforme Santos e Lima (2009, p. 78).

$$
R_{d}=\sum_{i=1}^{n} l_{i}
$$

$(\mathrm{km})$.

Onde: $R_{d}=$ rede de drenagem $(\mathrm{km}) ; l_{i}$ - comprimento dos cursos d'água

A densidade de drenagem foi calculada pela Equação (4) conforme Hiruma e Ponçano (1994, p. 52) utilizando o comprimento total dos cursos d'água e a área de drenagem.

$$
D d=\frac{R d}{A}
$$
da bacia $\left(\mathrm{km}^{2}\right)$.

Onde: $\mathrm{Dd}=$ densidade de drenagem; $\mathrm{Rd}=$ rede de drenagem $(\mathrm{km}) ; \mathrm{A}=$ área

Para a análise dos dados pluviométricos durante o período de estudo foi utilizado pluviômetro automático Delta $\operatorname{OHM} 2013-\mathrm{DB}(0,2 \pm 0,050 \mathrm{~mm})$ do Centro Nacional de Monitoramento e Alerta de Desastres Naturais (CEMADEN, 2018) instalado na confluência dos Ribeirões de Caldas e da Serra.

A freqüência das amostragens de água foi mensal, caracterizando as variações em um ano hidrológico, ou seja, de períodos seco e chuvoso, totalizando doze amostragens entre janeiro a dezembro do ano de 2017. As amostragens foram realizadas nos pontos: $(\mathrm{P} 1)=$ Ribeirão de Caldas; $(\mathrm{P} 2)=$ Ribeirão da Serra; $(\mathrm{P} 3)=$ Ribeirão de Poços início; (P4) Córrego do Parque; (P5) = Ribeirão de Poços trecho médio; (P6) = Córrego do Curtume; (P7) = Córrego da Cerâmica; (P8) = Ribeirão de Poços próximo ao exutório (Figura 1).

A vazão foi determinada utilizando-se uma régua limnimétrica para medir o nível da água do rio, trena de aço longa para a largura e micromolinete Flow Rate Sensor Vernier para velocidade $(0,0$ a $4,0 \mathrm{~m} / \mathrm{s} \pm 0,0012 \mathrm{~m} / \mathrm{s})$. A vazão foi estimada de acordo com a Equação (5) de acordo com Hermes e Silva (2004, p. 53).

$$
Q=P \times L \times V \times C
$$

Onde: $\quad Q=$ vazão $\left(\mathrm{m}^{3} / \mathrm{s}\right) ; P=$ profundidade do canal $(\mathrm{m}) ; L=$ largura do canal $(\mathrm{m}) ; \quad V=$ velocidade de escoamento no canal $(\mathrm{m} / \mathrm{s}) ; C=$ Coeficiente de correção (0,8 para rios com fundo rochoso e 0,9 para rios com fundo lodoso).

Nos pontos (P3) = Ribeirão de Poços, início, (P5) = Ribeirão de Poços, trecho médio, e, (P8) = Ribeirão de Poços, próximo ao exutório, a vazão do curso da água foi obtida por meio da Equação 6 de acordo com o principio do balanço de massa (vazão) de von Sperling (2007, p. 89).

$$
Q_{3}=Q_{e 1}+Q_{e 2}
$$

Estudos Geográficos, Rio Claro, 17(1): 68-90, jan./jun. $2019 \quad$ (ISSN 1678-698X) http://www.periodicos.rc.biblioteca.unesp.br/index.php/estgeo 
Onde: $Q_{3}=$ vazão após zona de mistura $\left(\mathrm{m}^{3} / \mathrm{s}\right) ; Q_{e 1}=$ vazão do afluente 1 antes da zona de mistura $\left(\mathrm{m}^{3} / \mathrm{s}\right) ; Q_{e 2}=$ vazão do afluente 2 antes da zona de mistura $\left(\mathrm{m}^{3} / \mathrm{s}\right)$.

O processo de amostragem, amostra composta, foi realizado em três pontos: $25 \%, 50 \%$ e $75 \%$ do comprimento da calha do rio, tomando uma margem como referência. As águas fluviais foram caracterizadas físico-quimicamente através de equipamento com eletrodos de leitura direta no próprio local de coleta, medidor portátil U-50 Multiparameter Water Quality Checkers da Horiba, previamente calibrado, sendo analisadas as seguintes variáveis: temperatura (Thermistor method -10 a $55^{\circ} \mathrm{C} \pm 0,3^{\circ} \mathrm{C}$ ); $\mathrm{pH}$ (Glass electrode method 0 a $14 \pm 0,1 \mathrm{pH}$ ); condutividade elétrica (4 AC electrod method 0 a $100 \mu \mathrm{S} / \mathrm{cm} \pm 0,1 \%$ ); oxigênio dissolvido (polarographic method 0 a $50 \mathrm{mg} / \mathrm{L} \pm 0,2 \mathrm{mg} / \mathrm{L}$ ); potencial redox (Platinun electrode method -2000 a $2000 \mathrm{mV} \pm 15 \mathrm{mV}$ ); sólidos totais dissolvidos (Condutctivity conversion 0 a $100 \mathrm{~g} / \mathrm{L} \pm 5 \mathrm{~g} / \mathrm{L}$ ) e turbidez (LED light source 0 a $800 \mathrm{NTU} \pm 1$ NTU).

Para a coleta de sólidos totais em suspensão (STS), foi utilizado amostrador do tipo USDH-48 ou AMS-1. As amostras, após coleta, foram armazenadas em vasilhames de polietileno e encaminhadas ao Laboratório de Ecossistemas Aquáticos e Solos (LEAS) do Instituto de Ciência e Tecnologia da Universidade Federal de Alfenas (ICT/UNIFAL).

As amostras coletadas em todos os pontos de amostragem, foram filtradas com membranas de $1,2 \mu \mathrm{m}$ acoplado a um conjunto kitassato ligado a uma bomba de vácuo para quantificação do teor de sólidos totais em suspensão, em triplicata, de acordo com Standard Methods for the Examination of Water and Wastewater (1999, p.220-222), segundo metodologia gravimétrica utilizando a Equação (7).

$$
S T S=\frac{P_{1}-P_{2}}{V_{\text {amostra }}}
$$

Onde: STS = concentração de Sólidos Totais em Suspensão $(\mathrm{mg} / \mathrm{l}) ; P 1=$ massa do filtro pesado após a filtração $(\mathrm{mg}), P 2=$ massa do filtro pesado antes da filtração (mg); $V=$ volume da amostra de água filtrada (I)

Nos pontos: (P3) = Ribeirão de Poços, início; (P5) = Ribeirão de Poços, trecho médio; (P8) = Ribeirão de Poços, próximo ao exutório; a concentração de sólidos totais em suspensão foi calculada por meio da Equação 8.

$$
C_{S T S}=\frac{Q_{e 1} \times S T S_{e 1}+Q_{e 2} \times S T S_{e 2}}{Q_{e 1}+Q_{e 2}}
$$

Onde: $\mathrm{C}_{\text {STS }}=$ concentração de sólidos totais em suspensão logo após a mistura (mg/L); $Q_{\mathrm{e} 1}=$ vazão do afluente 1 antes da zona de mistura $\left(\mathrm{m}^{3} / \mathrm{s}\right) ; \mathrm{Q}_{\mathrm{e} 2}=$ vazão do afluente 2 antes da zona de mistura $\left(\mathrm{m}^{3} / \mathrm{s}\right) ; \mathrm{STS}_{\mathrm{e} 1}=$ concentração de sólidos totais em suspensão no afluente 1 antes da zona de mistura $(\mathrm{mg} / \mathrm{L}) ; \mathrm{STS}_{\mathrm{e} 2}=$ concentração de sólidos totais em suspensão do afluente 2 antes da zona de mistura (mg/L).

Para simular o transporte específico anual de carga dissolvida e em suspensão foi necessário relacionar a concentração média ponderada com a vazão média durante todo o período de amostragem, estimando a quantidade total evacuada em toneladas por ano (Equação 9).

Estudos Geográficos, Rio Claro, 17(1): 68-90, jan./jun. $2019 \quad$ (ISSN 1678-698X) http://www.periodicos.rc.biblioteca.unesp.br/index.php/estgeo 


$$
C_{E}=\frac{\sum_{i=1}^{n} C_{i} \cdot Q_{i}}{\sum_{i=1}^{n} Q_{i}}
$$

Onde: $C_{E}$ é a concentração media ponderada pela vazão do parâmetro $(\mathrm{mg} / \mathrm{L}) ; C_{i}=$ a concentração do parâmetro para a quantificação $i(\mathrm{mg} / \mathrm{L}) ;$ e $Q_{i}=$ vazão do rio no dia da quantificação $i\left(\mathrm{~m}^{3} / \mathrm{s}\right)$.

\section{RESULTADOS E DISCUSSÕES}

\section{ANÁLISE FISIOGRÁFICA}

A bacia do Ribeirão de Poços está localizada em Poços de Caldas, região sul do estado de Minas Gerais (Figura 1), mais precisamente no Complexo Alcalino de Poços de Caldas, que representa uma caldeira vulcânica, e situa-se sobre o "Ramo NW", compreende uma suíte de rochas plutônicas e vulcânicas classificadas, principalmente, como fonolitos e nefelina sienitos (SCHORSCHER e SHEA, 1992, p. 27).



Figura 1 - Localização da bacia do Ribeirão de Poços em Poços de Caldas (MG) com pontos de amostragem:

$(\mathrm{P} 1)$ = Ribeirão de Caldas; $(\mathrm{P} 2)=$ Ribeirão da Serra; $(\mathrm{P} 3)$ = Ribeirão de Poços início; (P4) Córrego do Parque; $(\mathrm{P} 5)$ = Ribeirão de Poços trecho médio; $(\mathrm{P} 6)$ = Córrego do Curtume; (P7) = Córrego da Cerâmica; (P8) = Ribeirão de Poços próximo ao exutório. Localização da estação pluviométrica (EP).

Estudos Geográficos, Rio Claro, 17(1): 68-90, jan./jun. $2019 \quad$ (ISSN 1678-698X) http://www.periodicos.rc.biblioteca.unesp.br/index.php/estgeo 
$\mathrm{Na}$ bacia, que possui aproximadamente $12 \mathrm{~km}^{2}$, afloram rochas alcalinas tinguaítos, que correspondem à maior parte das rochas expostas no Complexo Alcalino de Poços de Caldas, possuem coloração acinzentada com texturas granulares ou sacaróides. Em menores proporções, encontram-se fonólitos com coloração cinza escura e textura porfirítica ou afanítica, e, nefelinas/foiaítos de granulação grosseira a média e coloração acinzentada clara (Figura 2A).

O planalto de Poços de Caldas localiza-se na borda ocidental da província da Mantiqueira e em contato com os extremos orientais da bacia sedimentar do Paraná, formando um conjunto morfoestrutural perfeitamente caracterizado (TINÓS et al., 2014, p.355). Segundo Moraes e Jiménez-Rueda (2008, p.197) a partir da análise do mapa morfoestrutural e dos principais lineamentos, determinou-se a ocorrência de trends de fraturas demonstrando que a área foi intensamente afetada por eventos tectônicos. Quanto ao relevo atual a área de estudo está localizada nas serras anelares onde predominan montanhas com topos restritos, e, no planalto do maciço alcalino interno com morros e morrotes de topos arredondados, colinas e planícies aluviais (Figura 2B).

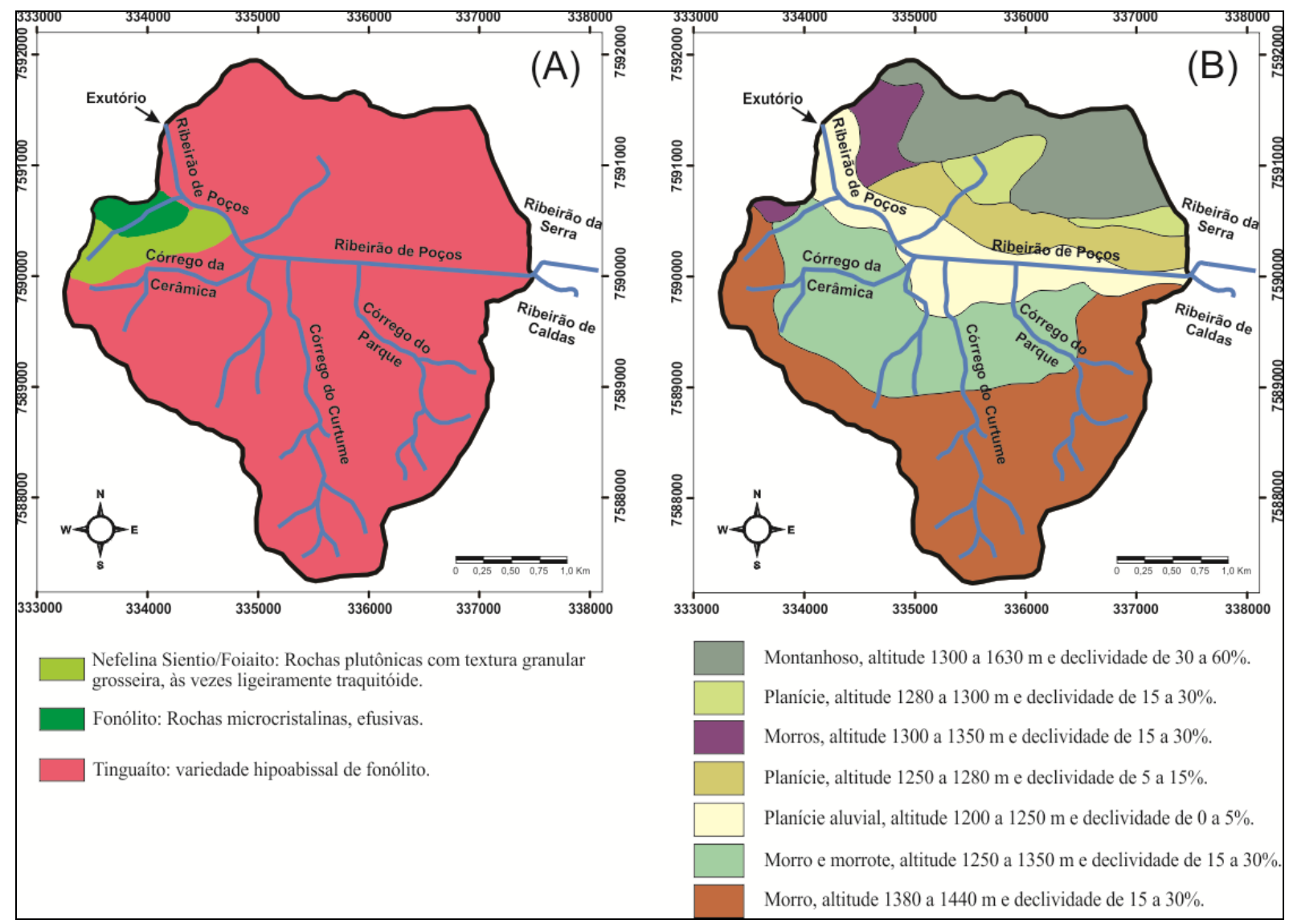

Figura 2 - (A) Geologia da bacia do Ribeirão de Poços. (B) Relevo da bacia do Ribeirão de Poços.

Fontes: (A) Ellert, 1959; (B) Zaine et al., 2008.

O clima na região da bacia, segundo a classificação de Köppen (1948) é do tipo Cwb mesotérmico com inverno seco e verão brando. Segundo a Prefeitura Municipal de Poços de Caldas (2006, p. 46) o clima é marcado pela ocorrência de duas estações distintas: o verão chuvoso, de outubro a março e inverno seco, nos meses de abril a setembro.

Estudos Geográficos, Rio Claro, 17(1): 68-90, jan./jun. 2019 (ISSN 1678-698X) http://www.periodicos.rc.biblioteca.unesp.br/index.php/estgeo 
$\mathrm{Na}$ área estudada afloram latossolos profundos, com pouca diferenciação entre horizontes, em relevos ondulados a suave ondulado. Solos rasos, cambissolos com sequência de horizontes $\mathrm{A}, \mathrm{Bi}$ e $\mathrm{C}$ ocorrem em relevos ondulados a forte ondulados. Neossolos afloram nos relevos montanhosos e/ou nas áreas serranas com topos restritos. Solos indiferenciados de várzea ocorrem nos relevos planos, pouco profundos, com características associadas a encharcamento e/ou deposição de material.

A região de estudo, apesar de estar situada no bioma Mata Atlântica, apresenta uma diversidade de biótopos, destacando-se a Floresta Estacional Semidecidual Montana e os Campos de Altitude, que representam um contexto transacional entre Mata Atlântica e Cerrado (MORAES; JIMÉNEZ-RUEDA, 2005, p. 256). Enquanto as espécies arbustivas predominam nos topos e vertentes, as formações arbóreas se encontram distribuídas nos taludes íngremes e próximas às galerias das nascentes dos principais rios da bacia.

A bacia do Ribeirão de Poços compreende a área de drenagem entre a confluência dos Ribeirões de Caldas e da Serra, ambos, drenam toda a área urbana do município. O Ribeirão de Caldas caracteriza-se pela concentração de estabelecimentos comerciais e residenciais, com adensamento no sentido da área central. No Ribeirão da Serra se concentram os maiores números de indústrias e núcleos residenciais isolados que estão se expandindo em direção ao centro (Figura 3).

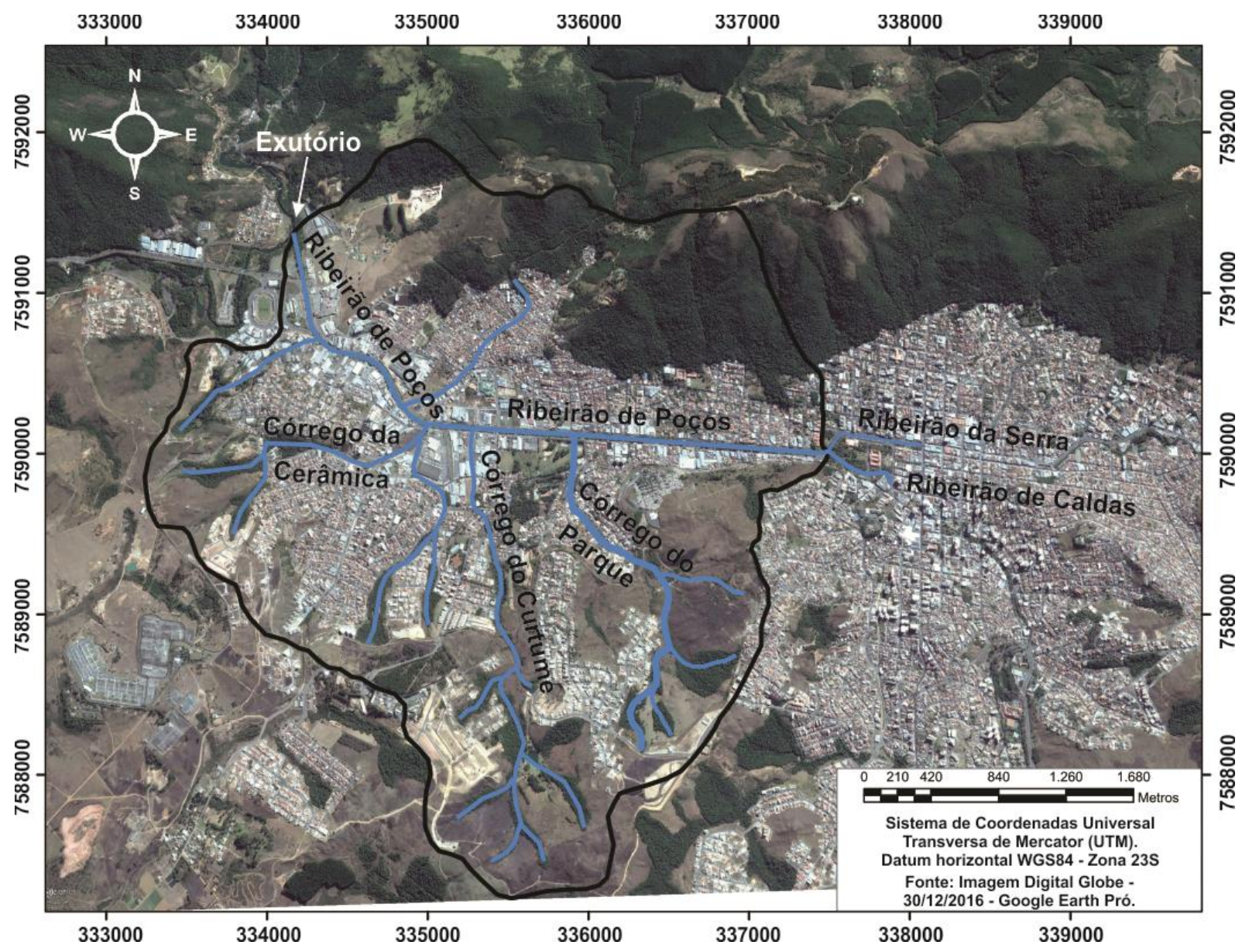

Figura 3 - Bacia do Ribeirão de Poços na área urbana de Poços de Caldas (MG). Fonte: Digital Globe do aplicativo Google Earth Pro, 2018.

Estudos Geográficos, Rio Claro, 17(1): 68-90, jan./jun. 2019 (ISSN 1678-698X) http://www.periodicos.rc.biblioteca.unesp.br/index.php/estgeo 
O desenvolvimento urbano de Poços de Caldas ocorreu principalmente devido as condições do meio físico, com a ocupação das vertentes dos principais rios, e, das áreas em direção às serras. Como o vale do Ribeirão de Poços apresenta áreas planas relativamente estreitas, o crescimento urbano prosseguiu pelas vertentes íngremes das colinas e morros vizinhos. Atualmente, o Ribeirão de Poços encontra-se retificado em praticamente toda sua extensão. Os maiores afluentes estão localizados na margem esquerda, que inclui os Córregos do Parque, Curtume e Cerâmica que, também apresentam significativa ocupação urbana (Figura 3).

\section{ANÁLISE MORFODINÂMICA}

O índice de sinuosidade foi calculado pelo comprimento do canal principal do Ribeirão de Poços $(4,18 \mathrm{~km})$ e o comprimento, em linha reta, do exutório até a nascente e/ou confluência dos pontos P1 e P2 $(3,43 \mathrm{~km})$. O resultado de 1,2 indica um canal retilíneo, pois, segundo Cunha (2017, p. 159) valores superiores a 1,5 definem um padrão meândrico, enquanto que a proximidade do valor 1,0 indica um canal retilíneo.

A rede de drenagem da bacia do Ribeirão de Poços é de 20,05 km e foi utilizada para calcular a densidade de drenagem. Segundo Stevaux e Latrubesse (2017, p. 66) a densidade de drenagem é o parâmetro que controla a eficiência de escoamento, refletindo mais diretamente, além da precipitação média, a influência do clima, do relevo, litologia, solo, cobertura vegetal e uso e ocupação. A densidade de drenagem da bacia é de $1,67 \mathrm{~km} / \mathrm{km}^{2}$, e, de acordo com Hiruma e Ponçano (1994, p. 52) corresponde a um valor intermediário $\left(1,25 \mathrm{~km} / \mathrm{km}^{2}<\mathrm{Dd}<2,50\right.$ $\mathrm{km} / \mathrm{km}^{2}$ ) controlado pela litologia e variação do relevo da Caldeira Vulcânica de Poços de Caldas.

O perfil longitudinal de um rio sofre contínuas flutuações, devido às variações no escoamento e na carga sólida, o que acarreta muitas irregularidades no seu leito como as corredeiras e as depressões (CUNHA, 2017, p.181). A bacia do Ribeirão de Poços possui uma extensão de $4,18 \mathrm{~km}$, e, escoa por um canal que apresenta a ampliação da calha e do fundo do vale em razão da diminuição da declividade nos setores (a, b, c e d) separados de acordo com seus principais tributários: $(\mathrm{P} 1)=$ Ribeirão de Caldas; $(\mathrm{P} 2)=$ Ribeirão da Serra; $(\mathrm{P} 4)$ Córrego do Parque; $(\mathrm{P} 6)$ = Córrego do Curtume; $(\mathrm{P} 7)$ = Córrego da Cerâmica (Figura 4).

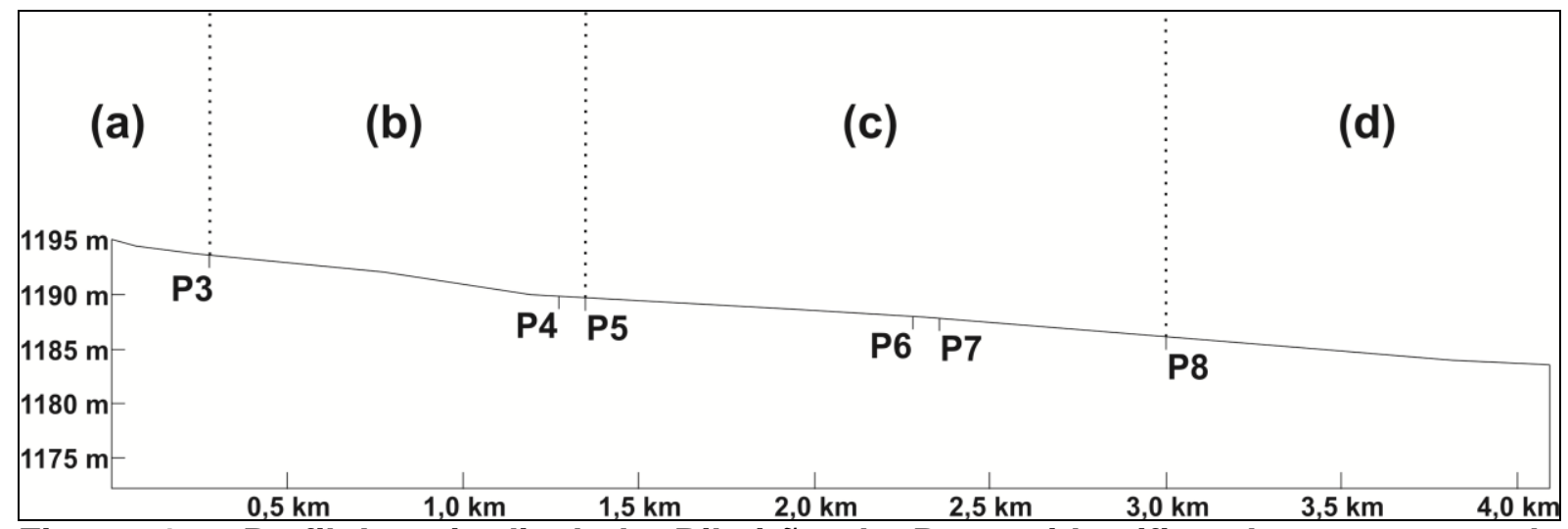

Figura 4 - Perfil Longitudinal do Ribeirão de Poços identificando os pontos de amostragem, a confluência com os principais tributários e os setores (a), (b), (c) e (d) do canal.

Estudos Geográficos, Rio Claro, 17(1): 68-90, jan./jun. 2019 (ISSN 1678-698X) http://www.periodicos.rc.biblioteca.unesp.br/index.php/estgeo 
Segundo Lucas e Cunha (2007, p. 46) as características da bacia de drenagem e as condições climáticas refletem diretamente nas características físicas dos canais fluviais.

"Contudo, os canais das bacias urbanizadas apresentam graus variados de desequilíbrio, dado pelas diferenças na distribuição e grau de urbanização, bem como, na intensificação de construções mais recentes, que resulta em variações na capacidade e eficiência do canal" (LUCAS e CUNHA 2007, p. 46).

Neste sentido, a morfologia do canal foi analisada através da relação entre as variáveis largura e profundidades do canal, durante os doze meses de amostragem, nos principais tributários do Ribeirão de Poços: $(\mathrm{P} 1)=$ Ribeirão de Caldas; (P2) = Ribeirão da Serra; (P4) Córrego do Parque; (P6) = Córrego do Curtume; (P7) = Córrego da Cerâmica (Figura 5).

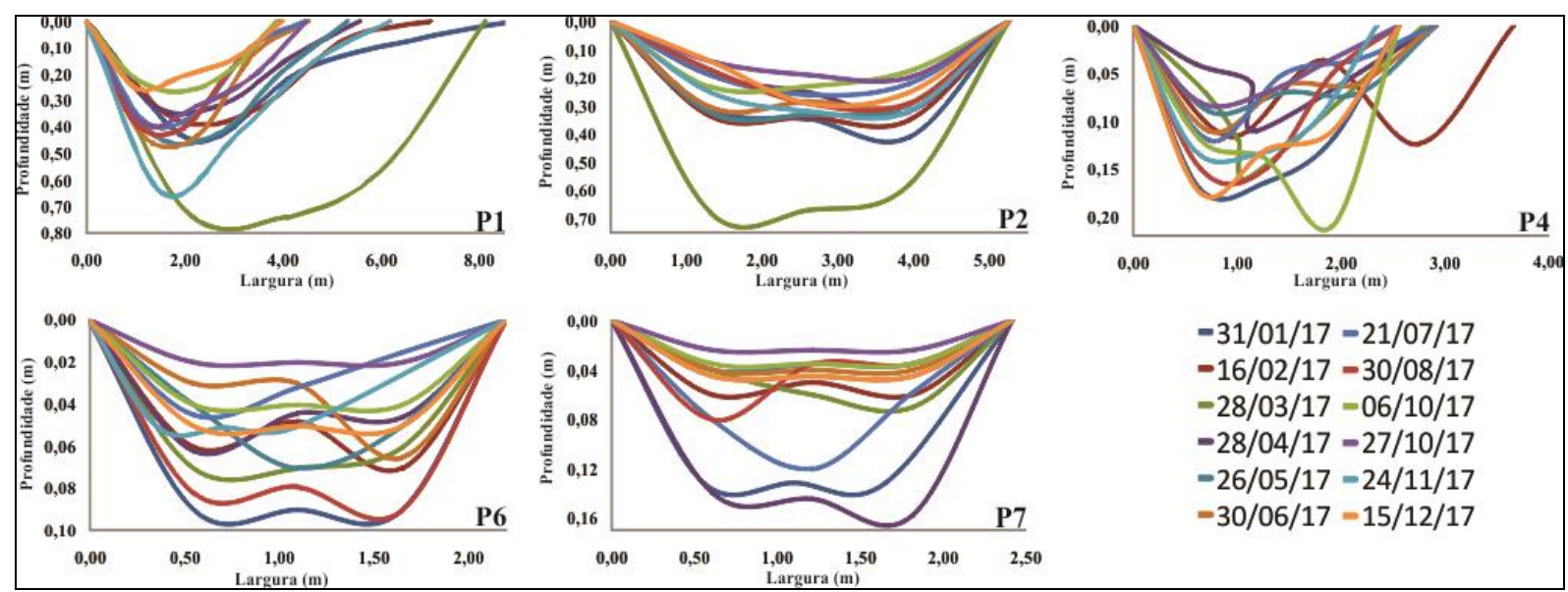

Figura 5 - Perfis transversais do canal dos afluentes do Ribeirão de Poços: (P1) = Ribeirão de Caldas; (P2) = Ribeirão da Serra; (P4) Córrego do Parque; (P6) = Córrego do Curtume; (P7) = Córrego da Cerâmica.

O setor (a - Figura 4) localiza-se entre as cotas de 1195 a $1193 \mathrm{~m}$ de altitude, com uma extensão de $0,30 \mathrm{~km}$, sendo formado pelo encontro dos Ribeirões de Caldas (P1) e da Serra (P2). O Ribeirão de Caldas é formado pelo Córrego Vai e Volta e Ribeirão Ponte Alta, apresenta uma produção visual de sedimentos, areia e cascalho, mais expressiva, suas águas são canalizadas, o rio é retificado e com as margens concretadas na área central de Poços de Caldas (Figura 6a). O perfil transversal traçado apresenta valores irregulares de largura $8,70 \mathrm{~m}$ a 3,86 m, e, profundidade do talvegue entre 0,10 e $0,74 \mathrm{~m}$ devido ao acúmulo de sedimentos em períodos menos chuvosos e aprofundamento da calha nos meses de maiores precipitações, janeiro e fevereiro, conforme Figura 5.

Por outro lado, o Ribeirão da Serra, formado pelos tributários Ribeirão da Serra manancial e médio, possui margens compostas por blocos rochosos, escoando com velocidade por um leito com grande quantidade de seixos e matacões, areia e material sólido em suspensão (Figura 6b). O perfil transversal traçado apresenta valores constantes de largura $5,25 \mathrm{~m}$ e valores irregulares de profundidade do talvegue entre 0,14 e $0,68 \mathrm{~m}$ contribuindo para os processos de entalhamento e erosão do leito, conforme Figura 5.

Estudos Geográficos, Rio Claro, 17(1): 68-90, jan./jun. $2019 \quad$ (ISSN 1678-698X) http://www.periodicos.rc.biblioteca.unesp.br/index.php/estgeo 

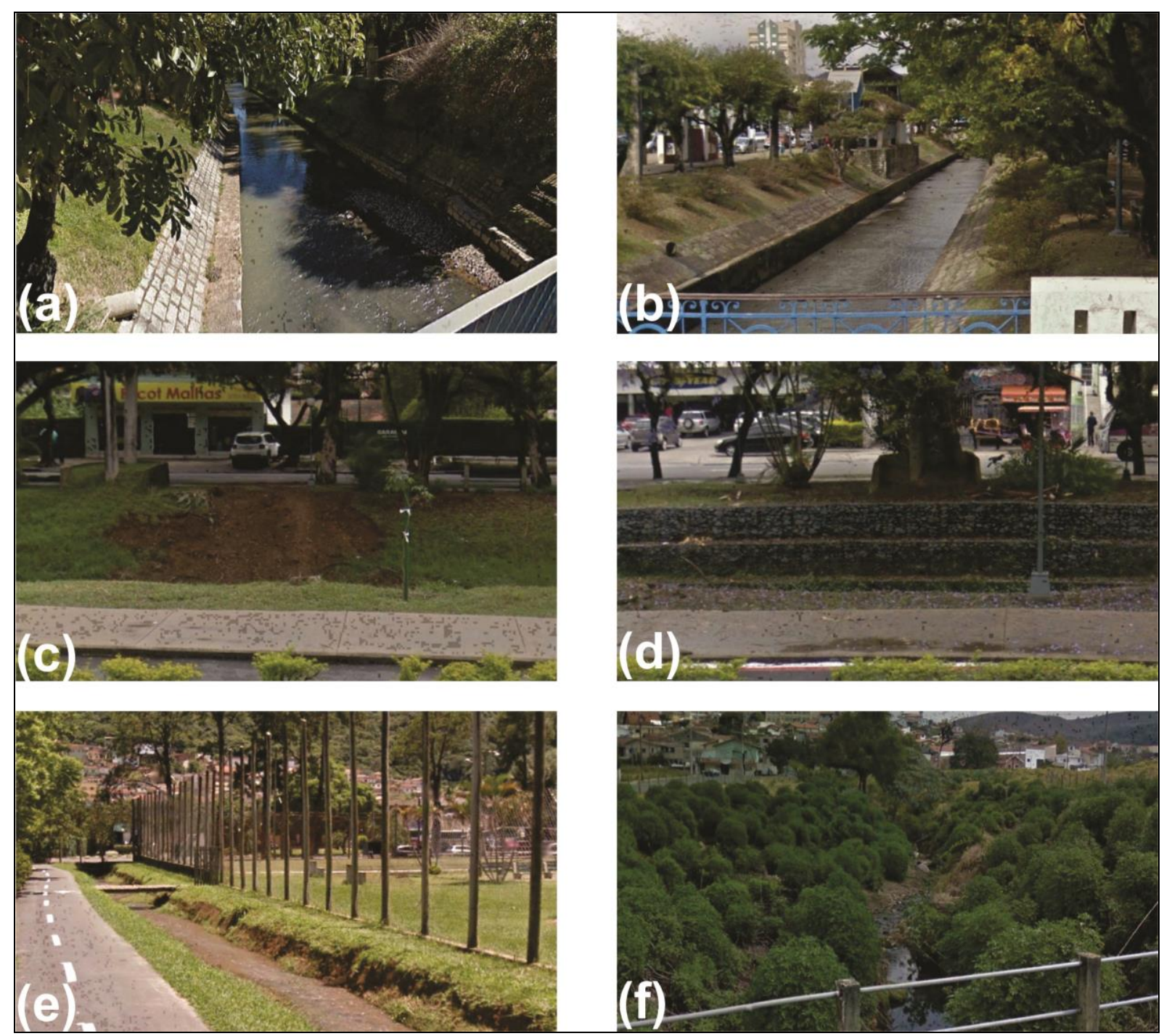

Figura 6 - (a) Ponto de amostragem no Ribeirão de Caldas. (b) Ponto de amostragem do Ribeirão da Serra. (c e d) Trecho entre os pontos P3 e P5 no Ribeirão de Poços. (e) Ponto de amostragem no Córrego do Parque. (f) Ponto de amostragem do Córrego da Cerâmica.

Fonte: Google Earth Pro, 2018.

O setor (b - Figura 4), praticamente retilíneo, drena a área urbana entre as cotas de 1193 a $1189 \mathrm{~m}$, recebendo a contribuição de diversas galerias de águas pluviais, lixos e materiais em suspensão. Os processos de entalhamento e erosão do leito podem ser evidenciados neste trecho pelas margens erodidas que caíram no leito do rio (Figura 6c), caracterizado por uma grande quantidade de areia, seixos e detritos, que estão recebendo manutenção, gaiola de gabião (Figura 6d), principalmente próximo à confluência com o Córrego do Parque (P4).

$\mathrm{O}$ córrego do Parque, que possui forma convexa e de vale em $\mathrm{V}$ em suas nascentes a aproximadamente 1320 metros de altitude, drena os bairros do Estado e São Geraldo até o Parque Municipal Antônio Molinari. Seus sedimentos caracterizam-se pela maior quantidade de material fino e areia que se acumulam no leito do rio que não é canalizado juntamente ao Parque Municipal, próximo ao exutório onde o vale é côncavo com acúmulo de água durante os períodos de maior precipitação (Figura 6e). Este trecho é o que apresenta maiores mudanças quanto à geometria, devido à velocidade de fluxo que se concentra na margem esquerda,

Estudos Geográficos, Rio Claro, 17(1): 68-90, jan./jun. 2019 (ISSN 1678-698X) http://www.periodicos.rc.biblioteca.unesp.br/index.php/estgeo 
enquanto na margem direita ocorre a deposição de sedimentos no talvegue. As larguras variam de $3,67 \mathrm{~m}$ a 2,35 $\mathrm{m}$, enquanto a profundidade de $0,21 \mathrm{~m}$ a $0,03 \mathrm{~m}$, conforme Figura 5.

Nos setores (c) e (d) entre as cotas 1189 a $1186 \mathrm{~m}$ e 1186 a $1183 \mathrm{~m}$, respectivamente, é possível observar a formação de bancos de areia $e$ assoreamento no leito do rio, provavelmente devido aos processos de erosão, margens erodidas que caíram no leito do rio (Figuras $6 \mathrm{c} \mathrm{e} \mathrm{d}$ ). No setor (c) há a contribuição dos Córregos do Curtume (P6) e da Cerâmica (P7 - Figura 6f). Os dois afluentes drenam áreas urbanas e de expansão urbana, fazendo com que os córregos transportem detritos e lixo que se acumulam em suas margens, e, também são transportados para a calha do Ribeirão de Poços (P8), conforme observados em campo. As calhas dos Córregos do Curtume (P6) e Cerâmica (P7) possuem valores constantes de largura $2,20 \mathrm{~m}$ e 2,42 m, e, valores irregulares de profundidade do talvegue entre 0,09 e 0,02 m e 0,16 m e 0,02, respectivamente (Figura 5).

\section{ANÁLISE PLUVIOMÉTRICA}

Para a análise dos dados pluviométricos durante o período de estudo, fez-se necessário obter os valores diários e totais mensais de precipitação dos meses de janeiro a dezembro de 2017 adquiridos pelo pluviômetro automático Delta OHM 2013-DB de Centro Nacional de Monitoramento e Alerta de Desastres Naturais. Em termos de totais pluviométricos, a precipitação anual registrada no período foi de 1.518,6 mm (Figura 7 e Tabela 1). Segundo Roldão et al., (2012, p. 521) o volume médio anual de chuvas na região é de $1553,1 \mathrm{~mm}$, ou seja, $34,5 \mathrm{~mm}$ acima do registrado no período de estudo.

Os meses mais chuvosos foram janeiro $(372,8 \mathrm{~mm})$ e novembro $(238,2 \mathrm{~mm})$, com maior distribuição de chuvas em 15 e 05 dias antes da amostragem do mês de janeiro (323,2 $\mathrm{mm}$ e 22,2 $\mathrm{mm}$ respectivamente). Na segunda amostragem de outubro uma precipitação expressiva ocorreu no dia da amostragem $(19,0 \mathrm{~mm}-$ Figura 4 e Tabela 1). Enquanto os meses de julho $(23,4 \mathrm{~mm})$ e agosto $(27,8 \mathrm{~mm})$ foram os de menores distribuições de chuvas (Figura 7 e Tabela 1).
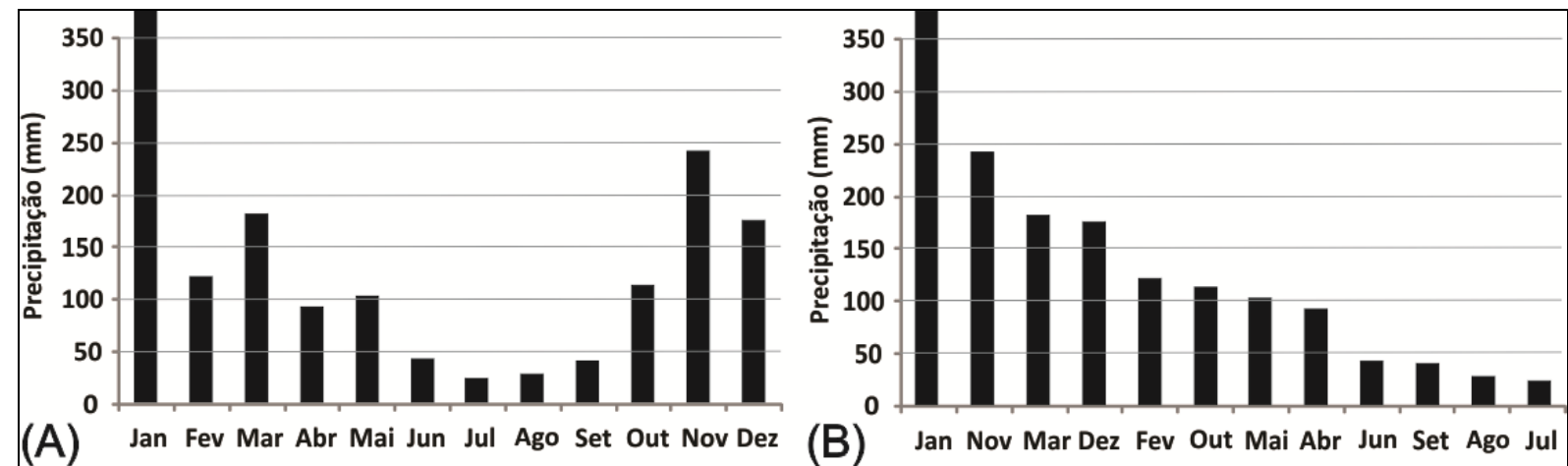

(A) Jan Fev Mar Abr Mai Jun Jul Ago Set Out Nov Dez

B) Jan Nov Mar Dez Fev Out Mai Abr Jun Set Ago Jul

Figura 7 - Valores de precipitação dos meses de janeiro a dezembro de 2017 adquiridos pelo pluviômetro automático Delta OHM 2013-DB do Centro Nacional de Monitoramento e Alerta de Desastres Naturais.

(A) Precipitação mensal. (B) Distribuição dos meses do ano por precipitação em ordem decrescente.

Fonte: CEMADEN, 2018.

Nos pontos (P1) Ribeirão de Caldas e (P2) Ribeirão da Serra, a análise morfométrica (Figura 5) indica um alargamento e aprofundamento da calha dos rios Estudos Geográficos, Rio Claro, 17(1): 68-90, jan./jun. 2019 (ISSN 1678-698X) http://www.periodicos.rc.biblioteca.unesp.br/index.php/estgeo 
no mês de março. Este alargamento pode estar relacionado ao acúmulo das chuvas que ocorreram nos meses de janeiro $(372,8 \mathrm{~mm})$, fevereiro $(120,0 \mathrm{~mm})$ e março $(179,8 \mathrm{~mm})$. Além disso, no mês de março houve chuvas acumuladas 15 dias $(88,2$ $\mathrm{mm}$ ) e 05 dias (3,4 $\mathrm{mm}$ ) antes da amostragem, e, precipitações de 8,4 $\mathrm{mm}$ no dia de amostragem (Tabela 1).

Tabela 1 - Valores de precipitação dos meses de janeiro a dezembro de 2017

\begin{tabular}{|c|c|c|c|c|}
\hline \multirow[t]{2}{*}{$\begin{array}{c}\text { Data de } \\
\text { amostragem }\end{array}$} & $\begin{array}{l}\text { Chuva } \\
\text { no mês }\end{array}$ & $\begin{array}{l}\text { Chuva } 15 \text { dias } \\
\text { antes da } \\
\text { amostragem }\end{array}$ & $\begin{array}{l}\text { Chuva } 05 \text { dias } \\
\text { antes da } \\
\text { amostragem }\end{array}$ & $\begin{array}{c}\text { Chuva no dia } \\
\text { da } \\
\text { amostragem }\end{array}$ \\
\hline & \multicolumn{4}{|c|}{$(\mathrm{mm})$} \\
\hline $31 / 01 / 2017$ & 372,8 & 323,2 & 22,2 & 3,6 \\
\hline $16 / 02 / 2017$ & 120,0 & 47,4 & 0,0 & 4,0 \\
\hline $28 / 03 / 2017$ & 179,8 & 88,2 & 3,4 & 8,4 \\
\hline $28 / 04 / 2017$ & 91,4 & 52,8 & 38,0 & 0,0 \\
\hline $26 / 05 / 2017$ & 100,6 & 82,6 & 20,8 & 0,0 \\
\hline $30 / 06 / 2017$ & 40,4 & 0,2 & 0,0 & 0,0 \\
\hline $21 / 07 / 2017$ & 23,4 & 23,2 & 22,8 & 0,2 \\
\hline $30 / 08 / 2017$ & 27,8 & 27,8 & 0,0 & 0,0 \\
\hline 06/10/2017 & 110,8 & 73,0 & 32,8 & 0,0 \\
\hline 27/10/2017 & 110,8 & 17,2 & 15,0 & 19,0 \\
\hline 24/11/2017 & 238,2 & 159,4 & 137,8 & 0,0 \\
\hline $15 / 12 / 2017$ & 173,2 & 80,0 & 4,6 & 0,0 \\
\hline
\end{tabular}

Fonte: CEMADEN, 2018.

Os Córregos do Parque (P4) e Curtume (P6) apresentam maiores valores de aprofundamento e alargamento no mês de janeiro, com 22,2 $\mathrm{mm}$ e 3,6 mm cinco dias antes e no dia de amostragem, respectivamente (Tabela 1). Por outro lado, o ponto (P7) Córrego da Cerâmica, apresenta os maiores valores de aprofundamento e alargamento da calha em abril $(91,4 \mathrm{~mm})$ com $52,8 \mathrm{~mm}$ e $38,0 \mathrm{~mm}$ quinze e cinco dias antes da amostragem (Tabela 1).

As chuvas constantes ao longo dos meses chuvosos podem ser os principais responsáveis pelas maiores modificações na morfologia dos canais (Tabela 1 e Figura 7). No entanto, cabe ressaltar que possíveis influências antrópicas, ocasionadas pela ocupação desordenada, a montante dos pontos analisados neste estudo, também podem influenciar no entalhamento dos canais estudados (Figura 5).

\section{ANÁLISE DA QUALIDADE DOS RECURSOS HÍDRICOS}

A urbanização se reflete sobre as questões ambientais, pois o crescimento rápido e sem planejamento tem contribuído para a deterioração dos espaços urbanos, gerando problemas de ordem social, econômica e ambiental (COSTA et al., 2018, p. 01). A criação de loteamentos pode constituir, em última instância, a expansão urbana, implicando a substituição de elementos naturais remanescentes por elementos construídos, num processo de transformação que afeta o equilíbrio da paisagem (CARVALHO, 2005, p. 73).

Os impactos também podem ser observados através da alteração topográfica de superfícies como resultado de novas construções e demolições, que ocorrem em uma variedade de escalas (McGRANE, 2016, p. 2297). Segundo

Estudos Geográficos, Rio Claro, 17(1): 68-90, jan./jun. $2019 \quad$ (ISSN 1678-698X) http://www.periodicos.rc.biblioteca.unesp.br/index.php/estgeo 
Chuerubim e Pavanin (2013, p. 230) os processos de expansão e transformação urbana podem proporcionar baixa qualidade de vida a parcelas significativas da população, bem como impactos negativos ao meio ambiente em que estão inseridas.

Nos últimos anos algumas fontes de poluição de recursos hídricos como esgotos sanitários, águas residuárias industriais, resíduos sólidos (lixo), águas de drenagem urbana, fontes acidentais e fontes atmosféricas passaram a assumir importância significativa (LUCAS e CUNHA 2007, p. 51). O homem promove profundas modificações no cenário natural, mediante atividades sociais, econômicas e políticas, com reflexo na urbanização, causando desequilíbrios no balanço hídrico de uma bacia (OLIVEIRA e CAMPOS, 2012, p. 199).

Segundo a Política Nacional de Recursos Hídricos o enquadramento dos corpos de água em classes, segundo os usos preponderantes da água, visa assegurar às águas qualidade compatível com os usos mais exigentes a que forem destinadas, diminuir os custos de combate à poluição das águas, mediante ações preventivas permanentes (BRASIL, 1997).

Além disso, as classes de corpos de água são estabelecidas pela legislação ambiental, e, enquanto não aprovados os respectivos enquadramentos, as águas doces serão consideradas Classe 2 (BRASIL, 2005). O Ribeirão de Poços não possui enquadramento, assim, todos os parâmetros analisados serão comparados com a Classe 2 da Resolução CONAMA 357.

A vazão de escoamento superficial ao longo do canal pode ser afetada pelas condições do tempo (precipitação), fisiografia da bacia de drenagem e atividades antrópicas. As maiores vazões foram registradas nos principais tributários e no Ribeirão de Poços no mês de março, final do período chuvoso $\left(P 1=5,36 \mathrm{~m}^{3} / \mathrm{s}, \mathrm{P} 2=\right.$ $3,57 \mathrm{~m}^{3} / \mathrm{s}, \mathrm{P} 3=8,93 \mathrm{~m}^{3} / \mathrm{s}, \mathrm{P} 5=9,0 \mathrm{~m}^{3} / \mathrm{s}$ e P $8=9,18 \mathrm{~m}^{3} / \mathrm{s}$ ). Nos Córregos do Parque (P4) e Curtume (P6) as maiores vazões foram em janeiro $0,14 \mathrm{~m}^{3} / \mathrm{s}$ e $0,16 \mathrm{~m}^{3} / \mathrm{s}$, respectivamente. Ja no ponto (P7) Córrego da Cerâmica o pico de vazão se deu no mês de abril $\left(0,22 \mathrm{~m}^{3} / \mathrm{s}\right)$. A média anual do Ribeirão de Poços (P8) foi de $2,16 \mathrm{~m}^{3} / \mathrm{s}$, menores e maiores valores registrados em março $\left(9,18 \mathrm{~m}^{3} / \mathrm{s}\right)$ e inicio de outubro $\left(0,52 \mathrm{~m}^{3} / \mathrm{s}\right)$, mostrando que este parâmetro também possui influência sazonal, diferença de $8,66 \mathrm{~m}^{3} / \mathrm{s}$ (Tabela 2 e Figura 8 ).

A temperatura é um fator que pode afetar a fauna e a flora aquáticas, quando ocorre o lançamento de efluentes industriais com temperaturas elevadas provocando a poluição térmica dos rios (LUCAS e CUNHA 2007, p. 52). O valor máximo de temperatura foi registrado em fevereiro no ponto $\mathrm{P} 7\left(26,0^{\circ} \mathrm{C}\right)$ e o menor no ponto $\mathrm{P} 1\left(15,9^{\circ} \mathrm{C}\right)$ em junho, podendo assim, observar uma variação de aproximadamente $10^{\circ} \mathrm{C}$ de temperatura da água entre os meses de verão (chuvoso) e o inverno (seco). Outro fator a se destacar é o aumento da temperatura média após a área urbana, fato devido provavelmente ao despejo de efluentes (Tabela $2 \mathrm{e}$ Figura 8), conforme verificado nos trabalhos de Souza e Tundisi (2003, p. 716) e Costa et al., (2018, p.10).

$\mathrm{O}$ valor máximo de $\mathrm{pH}$ (Tabela 2 e Figura 8 ) foi registrado no ponto P1 $(7,7)$ em setembro e o menor no ponto P6 $(3,3)$ em abril. Alterações no pH da água podem prejudicar a fauna e flora aquáticas, devendo ser mantido entre os valores 6,0 e 9,0 (LUCAS e CUNHA 2007, p. 52; BRASIL, 2005). Os valores médios obtidos em todos os pontos de amostragem indicam que as águas se encontram próximo à neutralidade (entre 6,0 e 9,0), no entanto, em P6 foram encontradas alterações Estudos Geográficos, Rio Claro, 17(1): 68-90, jan./jun. $2019 \quad$ (ISSN 1678-698X) http://www.periodicos.rc.biblioteca.unesp.br/index.php/estgeo 
bruscas que podem estar relacionados com despejos de efluentes, conforme observado no trabalho de Filho e Chui (2006, p. 170).

Tabela 2 - Resultados dos parâmetros amostrados na bacia do Ribeirão de Poços

\begin{tabular}{|c|c|c|c|c|c|c|c|c|c|c|c|c|c|c|c|c|}
\hline \multirow{2}{*}{ Data } & \multirow{2}{*}{${ }^{\top} \mathbf{Q}$} & \multirow{2}{*}{$\begin{array}{c}\mathbf{T} \\
\left({ }^{\circ} \mathrm{C}\right)\end{array}$} & \multirow[t]{2}{*}{$\overline{\mathrm{pH}}$} & \multirow[t]{2}{*}{${ }^{2} \mathrm{C}$} & \multirow[t]{2}{*}{${ }^{3}$ Turb } & ${ }^{4} \mathrm{OD}$ & ${ }^{5}$ STD & STS & \multirow[t]{2}{*}{10} & \multirow{2}{*}{$\begin{array}{c}\mathrm{T} \\
\left({ }^{\circ} \mathrm{C}\right)\end{array}$} & \multirow[t]{2}{*}{$\overline{\mathrm{pH}}$} & \multirow[t]{2}{*}{${ }^{2} \mathrm{C}$} & \multirow[t]{2}{*}{${ }^{3}$ Turb } & \multirow[t]{2}{*}{${ }^{4} \mathrm{OD}$} & \multicolumn{2}{|c|}{${ }^{5}$ STD ${ }^{6}$ STS } \\
\hline & & & & & & \multicolumn{3}{|c|}{$(m g / L)$} & & & & & & & $\overline{(m g}$ & \\
\hline & & & & Pontc & & & & & & & & & onto 2 & & & \\
\hline $1 / 17$ & 1,86 & 23,0 & 7,0 & 60 & 15,4 & 4,4 & 40 & 63 & 1,19 & 20,7 & 7,3 & 70 & 6,6 & 4,6 & 40 & 104 \\
\hline$/ 02 / 17$ & 1,62 & 22,9 & 7,0 & 50 & $11, \varepsilon$ & 5,3 & 3 & 58 & 0,92 & 21,5 & 7,1 & 60 & 12,2 & & & 98 \\
\hline 28/03/17 & 5,36 & 21,0 & 6,7 & 59 & 52 & 5,5 & 38 & 56 & 3,57 & 20,6 & 6,6 & 49 & 49,0 & & 32 & 97 \\
\hline $8 / 04 / 17$ & 0,84 & 21,3 & 7,0 & 71 & 14,9 & 4,0 & 47 & 18 & 0,57 & 20,7 & 7,1 & 117 & 15,2 & & 76 & 32 \\
\hline $20 / 6$ & 0,86 & 19,6 & 7,1 & 99 & 17,6 & 5,2 & 64 & 11 & 0,91 & 19,1 & 7,0 & 120 & 13,6 & & 70 & 19 \\
\hline 7 & 0,63 & 15,9 & 7,1 & 109 & 177,0 & 4,8 & 71 & 4 & 0,58 & 16,0 & 7,1 & 129 & 17,1 & 3,9 & 84 & 11 \\
\hline /17 & 0,35 & 16,9 & 7,1 & 144 & 6,8 & 4,5 & 94 & 0 & 0,39 & 16,6 & 7,1 & 135 & 9,9 & & 00 & 6 \\
\hline $30 / 08 / 17$ & 0,30 & 17,7 & 6,9 & 182 & 6 & 5,7 & 118 & 1 & 0,35 & 17,6 & 6,8 & 175 & & 3,5 & 114 & 3 \\
\hline 117 & 0,15 & 21,7 & 7,7 & 201 & 3, & 4,7 & 13 & 7 & 0,32 & 21,9 & 7,4 & 149 & 11,4 & & 97 & 21 \\
\hline /17 & 0,31 & 21,6 & 6,7 & 178 & 7,2 & 4,3 & 116 & 7 & 0,24 & 21,5 & 6,9 & 164 & 10,8 & 4,0 & 108 & 15 \\
\hline & 1,32 & 22,1 & 6,9 & 63 & 20,8 & 5,5 & & 0 & 0,57 & 20,5 & 7,3 & 106 & & 5 & & 22 \\
\hline & 0,49 & 21,9 & 6,8 & 115 & 4,1 & 4,6 & 7. & 4 & 0,34 & 21,2 & 6,8 & 128 & 5,6 & 3,7 & 84 & 9 \\
\hline & & & & Donto & & & & & & & & & onto 4 & & & \\
\hline 7 & 04 & 22,1 & 7,3 & 50 & $\overline{11,6}$ & 4,3 & $\overline{3}$ & 63 & 0,14 & 21,2 & 6,9 & 40 & 3,8 & 4,6 & & 8 \\
\hline & 2,54 & 21,9 & 7,3 & 70 & & 4 & 4 & 54 & 0,08 & 21,6 & 7,2 & 40 & & & & 4 \\
\hline & 8,93 & 20,9 & 6,6 & 28 & 110 & 4 , & 3 & 52 & 0,07 & 20,3 & 6,8 & 47 & 13 & & & 5 \\
\hline & 1,41 & 21,3 & 7,0 & 89 & 13 & $3, \varepsilon$ & 58 & 17 & 0,03 & 22,8 & 6,9 & 46 & 8 & 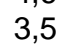 & & 4 \\
\hline & 1,77 & 19,7 & 7,0 & 110 & 15 & 5 , & 7 & 8 & 0,04 & 20,7 & 6,7 & 57 & & & & 2 \\
\hline & 1,20 & 16,1 & 7,3 & 113 & 90 & 4 & 74 &  & 0,02 & 16,2 & 7,1 & 59 & 0 & & & 1 \\
\hline & 0,74 & 16,9 & 7,1 & 132 & 7, & 3,8 & 87 & 2 & 0,01 & 16,8 & 7,2 & 58 & & & & 1 \\
\hline & 0,65 & 18,0 & 7,0 & 169 & 3, & 3 & 111 & 1 & 03 & 18,1 & 7,0 & 63 & & & & 0 \\
\hline & 0,47 & 21,6 & 6,7 & 144 & 5 & 3 & 01 & 10 & 00 & 22,2 & 7,2 & 63 & & & & 2 \\
\hline & 0,55 & 21,6 & 7,0 & 169 & 6 & 3 & 10 & 7 & 00 & 21,4 & 6,9 & 66 & 1 & & & 1 \\
\hline & 1,89 & 21,9 & 7,3 & 79 & 17 & 5 & & $\varepsilon$ & 03 & 21,5 & 7,0 & 63 & & & & 3 \\
\hline & 83 & 21,7 & 7,2 & 120 & 4, & 3 & & 5 & 0,02 & 21,4 & 7,1 & 57 & 0, & & & 2 \\
\hline & & & & Ponto & & & & & & & & & onto 6 & & & \\
\hline & 18 & 22,2 & 7,1 & 60 & 11 & 4 & & 61 & 0,16 & 22,7 & 5,8 & 40 & 553 & & & 52 \\
\hline & 2,62 & 23,2 & 6,9 & 30 & 8 & 4 & & & 10 & 24,5 & 6,6 & 40 & & & & 51 \\
\hline & 9,00 & 20,9 & 7,1 & 65 & & & & & & 20,4 & 5,5 & 35 & & & & 47 \\
\hline & 1,44 & 21,4 & 6,8 & 97 & & 3 & 6 & 17 & 06 & 21,2 & 3,3 & 42 & 2 &, 5 & & 20 \\
\hline & 1,81 & 20,2 & 6,9 & 120 & & & & 0 & 05 & 21,2 & 6,7 & 70 & & & & 12 \\
\hline & & 16,2 & 7,2 & 117 & & & & & & 16,7 & 6,5 & 69 & & & & 8 \\
\hline & 0,75 & , & 7,1 & 125 & & & 8 & & & 17,3 & 6,9 & 6 & & & & 5 \\
\hline & & & 7,0 & 266 & & & & 1 & & 20,0 & 6,4 & 6( & & & & 2 \\
\hline & 0,47 & 24,0 & 7,4 & 142 & 11 & 3 & 9 & 10 & 3 & 21,4 & 7,0 & 74 & & 2 , & & 12 \\
\hline & & & 6,9 & 153 & & & & 7 & & & 60 & 83 & & & & 9 \\
\hline & 1,92 & 22,6 & 6,9 & 21 & 17 & 5 & 1 & 8 & 3 & 22,7 & 6,0 & 43 & 1 & & & 14 \\
\hline & 0,85 & 1 & 7,0 & 115 & & 3 & 75 & 5 & & 20,8 & 6,7 & 54 & & 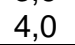 & 35 & 4 \\
\hline & & & & Pontc & & & & & & & & & onto $8^{*}$ & & & \\
\hline & 0,16 & 22,2 & 7,0 & 87 & 5 & & 56 & 18 & 0 & 22,6 & 6,5 & 26 & 852 & & & 104 \\
\hline & & & G & Gn & & & & & & 24,0 & 0,0 &  & & & & 00 \\
\hline & 0,08 & 21,4 & 7,1 & 8 & & & & 12 & & 21,0 & 6,9 & 3 & & & & 97 \\
\hline & 0,22 & 21,6 & 6,7 & 9 & & & & . & & 21,5 & 6,8 & $9 y$ & & & & 32 \\
\hline & 0,01 & 20,8 & 6,8 & 9 & & 3 & 6 & 5 & & 20,7 & 6,8 & 116 & & & & 19 \\
\hline & 0,01 & & 7,1 & 96 & & & 6 & 4 & & $\begin{array}{l}16,7 \\
\text { (1) }\end{array}$ & 7,2 & 115 & & & & 11 \\
\hline & 0,04 & 18,6 & 7,1 & 102 & 64 & 4 & 6 & 4 & & 17,5 & 7,2 & 128 & & & & 6 \\
\hline & 0,01 & 20,1 & 7,0 & 127 & 6 & & 8 & 2 & & 20,3 & 7,1 & 152 & & & & 3 \\
\hline & 0,01 & 23,1 & 7,2 & 108 & 1 & 2 , & 70 & 3 & 0,52 & 25,2 & 7,4 & 142 & & & & 21 \\
\hline & 0,00 & 22,3 & 3,7 & 122 & 1 & 4,2 & 8 & 4 & 0,57 & 23,2 & 6,6 & 100 & & 4 & 6 & 15 \\
\hline & 0,01 & 22,1 & 6,6 & 107 & 9 & 3 & 4 & 10 & & 23,4 & 7,1 & 73 & 135,0 & 4 & & 22 \\
\hline $15 / 12 / 17$ & 0,01 & 21,9 & 6,7 & 99 & 0,5 & 3,2 & 64 & 3 & 0,90 & 22,7 & 6,9 & 118 & 4,4 & 3,4 & 77 & 9 \\
\hline
\end{tabular}

$\mathrm{Q}=$ Vazão $\left(\mathrm{m}^{3} / \mathrm{s}\right) ;{ }^{2} \mathrm{C}=$ Condutividade $(\mu \mathrm{S} / \mathrm{cm}) ;{ }^{3} \mathrm{Turb}=$ Turbidez (NTU); ${ }^{4} \mathrm{OD}=$ Oxigênio Dissolvido; ${ }^{5} \mathrm{STD}=$ Sólidos Totais Dissolvidos; ${ }^{6} \mathrm{STS}=$ Sólidos Totais em Suspensão; ${ }^{*} \mathrm{Q}=$ estimada segundo Equação 6 e STS = estimada segundo Equação 8.

Estudos Geográficos, Rio Claro, 17(1): 68-90, jan./jun. 2019 (ISSN 1678-698X) http://www.periodicos.rc.biblioteca.unesp.br/index.php/estgeo 
Através da condutividade é possível: quantificar os macronutrientes; obter informações sobre a produção primária (reduz a condutividade) e a decomposição (aumenta a condutividade); identificar as fontes poluidoras; e identificar as diferenças hidrogeoquímicas, dente outras (PORTO, 1991, p. 378). Os menores valores de condutividade elétrica foram obtidos no ponto $\mathrm{P} 6=$ média anual de 56 $\mu \mathrm{S} / \mathrm{cm}$ ), e, os maiores nos Ribeirões de Caldas e da Serra ( $\mathrm{P} 1=$ média aual de 111 $\mu \mathrm{S} / \mathrm{cm}$ e P2 $=$ média anual de $117 \mu \mathrm{S} / \mathrm{cm}$ ). Apesar do intemperismo das rochas poder elevar a condutividade, acredita-se que estes valores podem estar relacionados, principalmente à contribuição de efluentes e ao volume de chuvas. Os maiores valores de condutividade foram observados entre os meses de maio a outubro, meses de menores precipitações (Figura 8 e Tabela 1) na maioria dos pontos amostrados (Tabela 2).



Figura 8 - Média anual dos parâmetros analisados na bacia hidrográfica do Ribeirão de Poços.

Um dos principais parâmetros de qualidade das águas capaz de demonstrar alterações na dinâmica hidrossedimentar de uma bacia como conseqüência da erosão acelerada é a turbidez (RAPOSO et al., 2009, p. 2). No entanto, segundo Von Sperling, (1996, p.24) a turbidez da água também pode estar associada a outras características como, sólidos em suspensão e matéria orgânica. Os valores medidos ao longo da bacia registraram grande variação durante os meses de coleta, sendo os maiores obtidos na calha principal do Ribeirão de Poços (Tabela 2). O limite de turbidez estabelecido pela Resolução CONAMA 357/2005 para rios de

Estudos Geográficos, Rio Claro, 17(1): 68-90, jan./jun. 2019 (ISSN 1678-698X) http://www.periodicos.rc.biblioteca.unesp.br/index.php/estgeo 
Classe 2 é de até 100 NTU (BRASIL, 2005) o qual foi excedido em algumas das amostras efetuadas neste trabalho, como no mês de março (P3 = 110 NTU e P5 = 267 NTU).

Segundo (Von Sperling, 1996, p.34) dentre os gases dissolvidos na água, o oxigênio é um dos mais importantes na dinâmica e caracterização de ecossistemas aquáticos. Ele é um dos principais parâmetros de caracterização dos efeitos da poluição das águas decorrentes dos despejos orgânicos, já que para o processo de decomposição são consumidos altos índices de oxigênio (LUCAS e CUNHA, 2007, p.54). Como pode ser observado na Tabela 2, há variação dos valores de oxigênio dissolvido em todos os pontos de amostragem. Os maiores valores de oxigênio dissolvido foram obtidos nos pontos P1 (média anual de 4,9 mg/L) e P4 (média anual de $4,8 \mathrm{mg} / \mathrm{L}$ ). A menor concentração foi encontrada no ponto P8 (média anual de 3,7 $\mathrm{mg} / \mathrm{L}$ ), fato que pode ser atribuído a decomposição de matéria orgânica (por oxidação) oriunda dos efluentes domésticos (Figura 8). Os valores, na maioria dos pontos amostrados, encontram-se abaixo do permitido (5,0 mg/l) para rios de Classe 2 (BRASIL, 2005).

\title{
ANÁLISE DO TRANSPORTE DE SEDIMENTOS
}

A concentração de sólidos nos ecossistemas aquáticos pode estar relacionada à litologia, geomorfologia, precipitação, pedologia, uso da terra e interferências antrópicas, e, o monitoramento regular pode servir para detectar tendências de aumento e/ou diminuição da erosão e interferências de uso da terra na bacia hidrográfica. Com isso:

\begin{abstract}
A intensa ocupação urbana e industrial vêm se tornando uma constante preocupação de políticas públicas para mitigar questões de preservação de nascentes e cursos de água, e, o uso indevido do solo tem originado processos erosivos influentes no assoreamento de rios, represas, lagos, ocasionando dificuldades na depuração das águas, com conseqüências negativas ao ambiente natural e seres vivos (OLIVEIRA et al., 2014, p. 278).
\end{abstract}

Para se conhecer o transporte anual de sedimentos dissolvidos e em suspensão (t/ano), é necessário relacionar os dados da bacia do Ribeirão de Poços e seus afluentes com a vazão média $(\mathrm{L} / \mathrm{s})$ e a concentração média ponderada para sólidos totais dissolvidos (STD) e sólidos totais em suspensão (STS) em (mg/L), conforme a Equação 9. A Tabela 3 apresenta os dados da vazão média de cada ponto de amostragem, e a média ponderada pela vazão $\left(\mathrm{C}_{\mathrm{E}}\right)$, assim como 0 transporte anual para sólidos totais dissolvidos e em suspensão da bacia.

A composição química da água de um rio depende das entradas naturais ou antropogênicas que ocorrem durante o seu percurso, desde as nascentes até a foz, fazendo parte de sua carga total dissolvida (OLIVEIRA et al., 2014, p. 278). A carga dissolvida é composta de material em solução transportado pelo rio, inclui substâncias inorgânicas e orgânicas e tem uma contribuição significativa para a carga total transportada pelos rios (STEVAUX e LATRUBESSE 2017, p. 120). A concentração média ponderada pela vazão, próximo ao exutório é de ( $\mathrm{P} 8=41,81$ $\mathrm{mg} / \mathrm{L})$, sendo a mais alta registrada no ponto P2 $(56,28 \mathrm{mg} / \mathrm{L})$ e a mais baixa em P4 $(34,31 \mathrm{mg} / \mathrm{L})$. Os resultados indicam um transporte total de 2854,88 toneladas de carga dissolvida por ano (Tabela 3).

Estudos Geográficos, Rio Claro, 17(1): 68-90, jan./jun. 2019 (ISSN 1678-698X) http://www.periodicos.rc.biblioteca.unesp.br/index.php/estgeo 
Tabela 3 - Valores de vazão média, média ponderada pela vazão e transporte anual de sedimentos dissolvidos e em suspensão na bacia do Ribeirão de Poços

\begin{tabular}{rrrrrr}
\hline & & \multicolumn{2}{c}{ Média ponderada $\left(\mathbf{C}_{\mathrm{E})}\right.$} & \multicolumn{2}{c}{ Transporte anual } \\
\cline { 3 - 6 } Ponto & $\begin{array}{c}\text { Vazão média } \\
\text { (L/s) }\end{array}$ & $\begin{array}{c}\text { STD } \\
\text { (mg/L) }\end{array}$ & \multicolumn{1}{c}{$\begin{array}{c}\text { STS } \\
\text { (mg/L) }\end{array}$} & $\begin{array}{c}\text { STD } \\
\text { (t/ano) }\end{array}$ & $\begin{array}{c}\text { STS } \\
\text { (t/ano) }\end{array}$ \\
\hline P1 & 1174,42 & 48,27 & 39,36 & 1787,79 & 1457,87 \\
P2 & 828,08 & 56,28 & 31,38 & 1469,67 & 819,42 \\
P3 & 2002,5 & 52,21 & 36,06 & 3297,24 & 2277,29 \\
P4 & 38,92 & 34,31 & 4,73 & 42,11 & 5,81 \\
P5 & 2041,42 & 48,58 & 35,49 & 3127,65 & 2285,02 \\
P6 & 68,58 & 35,92 & 26,31 & 77,69 & 56,9 \\
P7 & 55,33 & 55,32 & 11,15 & 96,54 & 19,45 \\
P8 & 2165,33 & 41,81 & 65,93 & 2854,88 & 4502,39 \\
\hline
\end{tabular}

A fim de verificar o comportamento de sólidos totais dissolvidos no exutório do Ribeirão de Poços (P8), foram realizadas correlações com a vazão (Figura 9a), condutividade (Figura 9b) e turbidez (Figura 9c). Os valores de sólidos totais dissolvidos aumentam com a diminuição da vazão, assim como para turbidez, fato provavelmente relacionado a um maior tempo de interação água-rocha-solo e contribuição das águas subterrâneas que podem alimentar o Ribeirão de Poços durante o período seco. Além disso, este fator também pode estar relacionado ao menor efeito da diluição de possíveis despejos "in natura" de efluentes domésticos ou industriais advindos principalmente dos Ribeirões de Caldas (P1) e da Serra (P2). A maior concentração de íons dissolvidos, também contribui para a elevação dos valores de condutividade elétrica obtidos no exutório da bacia (Figura 9).

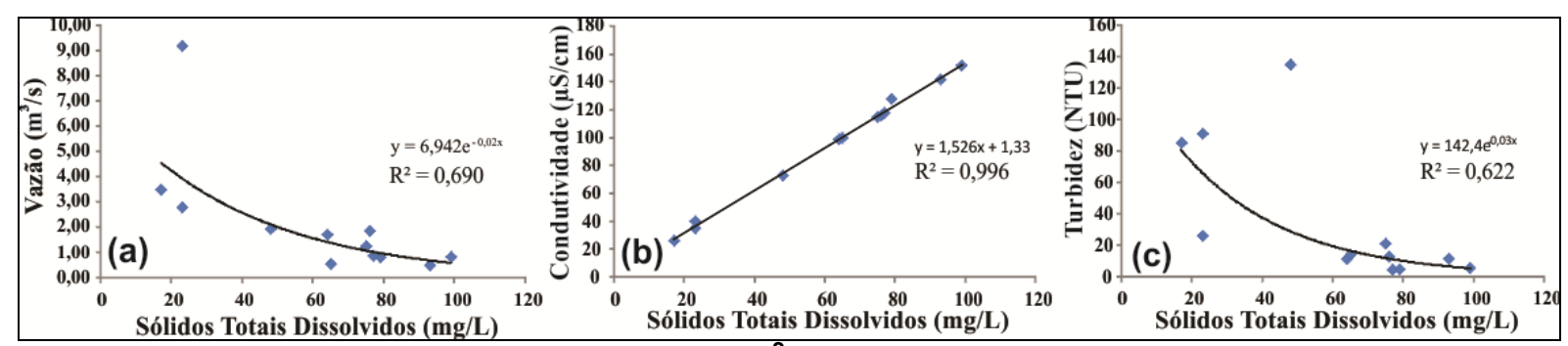

Figura 9 - (a) Correlação entre vazão $\left(\mathrm{m}^{3} / \mathrm{s}\right)$ e sólidos totais dissolvidos $(\mathrm{mg} / \mathrm{L})$; (b) correlação entre condutividade $(\mu \mathrm{S} / \mathrm{cm})$ e sólidos totais dissolvidos $(\mathrm{mg} / \mathrm{L})$; (c) correlação entre turbidez (NTU) e sólidos totais dissolvidos (mg/L).

A carga suspensa de um rio é constituída por material geralmente inferior à areia fina que é carregado por suspensão a uma velocidade muita próxima à do fluxo da água (STEVAUX e LATRUBESSE 2017, p. 124). Segundo Horowitz (2009, p. 342) o aumento da erosão das camadas superficiais do solo e das margens dos rios, associados com uma variedade de constituintes contribuem para o aumento dos sedimentos em suspensão nas águas dos rios. A concentração média ponderada pela vazão de sólido total em suspensão no Ribeirão de Poços, próximo ao exutório é de (P8 = 65,93 mg/L), sendo a mais alta registrada no ponto P1 $(39,36$ $\mathrm{mg} / \mathrm{L})$ e o mais baixa em P4 (4,73 mg/L). As concentrações de sólidos totais em suspensão aumentaram ao longo da bacia, e, com o aumento da vazão, arraste por

Estudos Geográficos, Rio Claro, 17(1): 68-90, jan.jun. 2019 (ISSN 1678-698X) http://www.periodicos.rc.biblioteca.unesp.br/index.php/estgeo 
erosão e contribuição das bacias tributárias, que resultam em um transporte de 4502,39 toneladas por ano (Tabela 3).

As correlações da Figura 10 indicam que os valores diminuem na época de menor vazão e/ou período seco (Figura 10a), assim como ocorre para a turbidez (figura 10c), fato inverso ao verificado para os sólidos totais dissolvidos e condutividade (Figura 10b). Isto se deve muito provavelmente a um menor arraste de sedimentos transportados pela erosão laminar, que é muito acentuada nos períodos chuvosos, contribuindo para a mudança dos perfis transversais dos canais analisados durante o período chuvoso neste estudo.
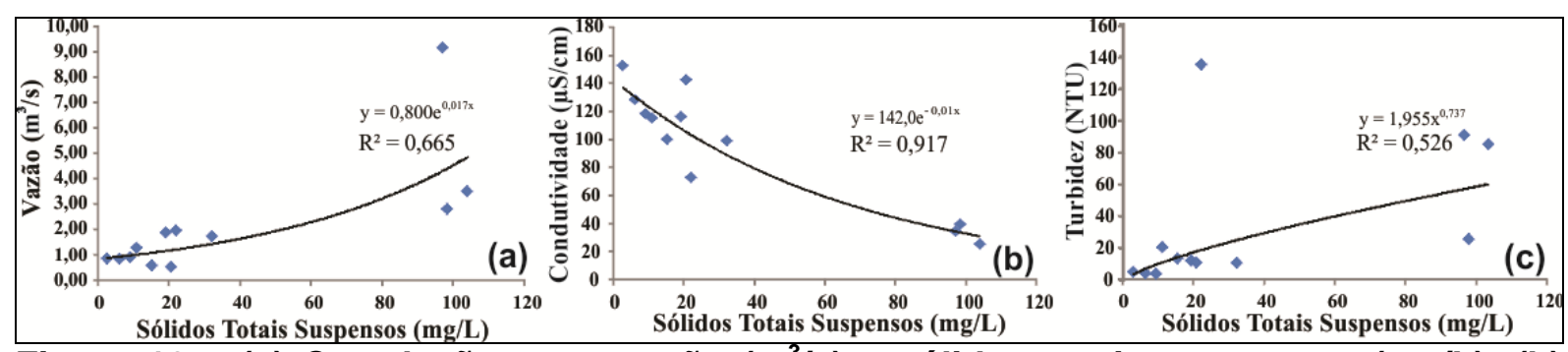

Figura 10 - (a) Correlação entre vazão $\left(\mathrm{m}^{3} / \mathrm{s}\right)$ e sólidos totais suspensos (mg/L); (b) correlação entre condutividade $(\mu \mathrm{S} / \mathrm{cm})$ e sólidos totais suspensos $(\mathrm{mg} / \mathrm{L})$; (c) correlação entre turbidez (NTU) e sólidos totais suspensos (mg/L).

O fluxo instantâneo diário pode ser obtido por meio das concentrações de sólidos totais dissolvidos e sólidos totais em suspensão próximo ao exutório do Ribeirão de Poços (P8) e as respectivas vazões registradas nos dias de amostragem. Este parâmetro é uma função de descarga (vazão), com a maioria da carga de sólidos em suspensão sendo transportados durante os meses mais chuvosos e úmidos e a carga de sólidos dissolvidos durante os períodos menos chuvosos e secos (CONCEIÇÃO et al., 2015, p. 45; FERNANDES et al., 2016, p. 58). Utilizando a média ponderada da concentração de sólidos analisadas neste estudo (Tabela 3), no ponto P8 (sólidos totais dissolvidos $=41,81 \mathrm{mg} / \mathrm{L}$ e sólidos toais suspensos $=65,93 \mathrm{mg} / \mathrm{L}$ ), a vazão média neste mesmo local de coleta $(2165,33 \mathrm{~L} / \mathrm{s})$, é possível calcular a média da quantidade de material removido anualmente, o que corresponde a 7357,27 t/ano (Figura 11).

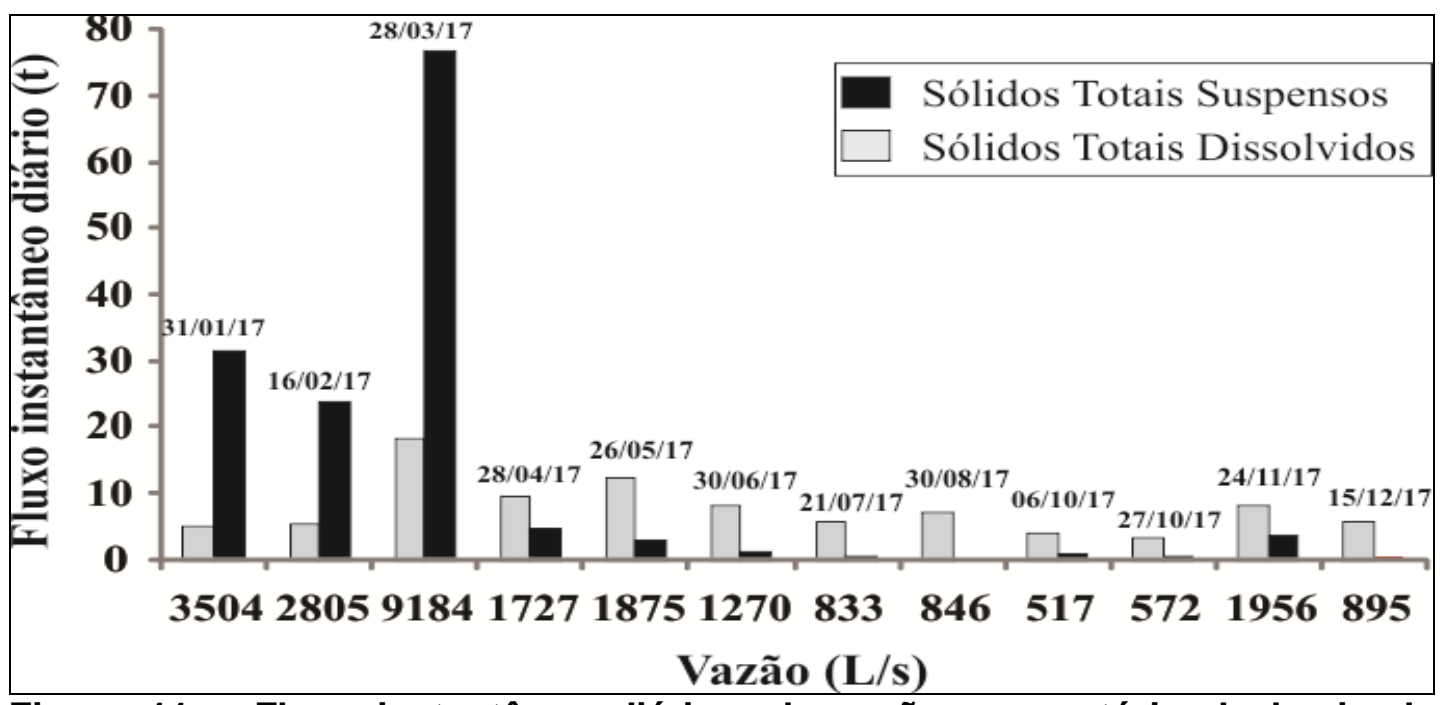

Figura 11 - Fluxo instantâneo diário pela vazão no exutório da bacia do Ribeirão de Poços.

Estudos Geográficos, Rio Claro, 17(1): 68-90, jan./jun. 2019 (ISSN 1678-698X) http://www.periodicos.rc.biblioteca.unesp.br/index.php/estgeo 
Análise geoambiental...

\section{CONSIDERAÇÕES FINAIS}

A análise fisiográfica, ocupação de vertentes dos principais rios, e, áreas em direção às serras, atrelados com a análise pluviométrica, verão chuvoso em janeiro $(319,2 \mathrm{~mm})$, fevereiro $(139,2 \mathrm{~mm})$ e março $(200,2 \mathrm{~mm})$ e inverno seco em junho $(29,8 \mathrm{~mm})$, julho $(0,8 \mathrm{~mm})$ e agosto $(14,8 \mathrm{~mm})$ podem ser os principais responsáveis pelas maiores modificações na analise da morfologia dos canais, qualidade dos recursos hídricos e transporte de sedimentos. Estas características podem estar influenciando no regime natural do Ribeirão de Poços e nos resultados das analises geoambientais. Este tipo de desenvolvimento urbano ocorre principalmente devido às características do meio físico e à tendência de áreas impróprias para a ocupação.

Com isso, o entalhamento dos canais estudados, pode estar sendo afetado pela urbanização e impermeabilização do solo, aumentando a velocidade de fluxo e o transporte de sedimentos pela calha dos rios. Estes fatores podem vir a acarretar inundações e alagamentos na área central do município, observadas pela variação nos valores de vazão, próximo ao exutório de $8,66 \mathrm{~m}^{3} / \mathrm{s}$. Para a análise da qualidade dos recursos hídricos e do transporte de sedimentos observou-se que, na maior parte dos parâmetros estudados, há elevação após a região da área urbana de Poços de Caldas. Ao contrário das concentrações de oxigênio dissolvido onde os valores, na maioria dos pontos amostrados, encontram-se abaixo do permitido pela legislação vigente de $5,0 \mathrm{mg} / \mathrm{L}$.

As águas da bacia do Ribeirão de Poços, segundo a legislação vigente, podem ser destinadas: ao abastecimento para consumo humano, após tratamento convencional; à proteção das comunidades aquáticas; à recreação de contato primário; à irrigação de hortaliças, plantas frutíferas e de parques, jardins, campos de esporte e lazer; e à aqüicultura e à atividade de pesca. Apesar do suporte da legislação ambiental vigente, o município não possui um plano efetivo de controle, monitoramento e fiscalização ambiental para a bacia do Ribeirão de Poços. É preciso concretizar uma política publica integrada, englobando uma ação coordenada pelo poder executivo municipal com a participação dos setores de fiscalização ambiental, visando o controle do crescimento urbano e um programa de monitoramento na bacia hidrográfica e seus afluentes.

\section{REFERÊNCIAS}

ALMEIDA, L.Q. Contexto geoambiental como subsídio ao zoneamento ecológicoeconômico de Maracanaú, região metropolitana de Fortaleza. Estudos Geográficos, Rio Claro, v. 7, p. 125-146, 2009.

BRASIL. Resolução CONAMA n³57, de 17 de março de 2005. Dispõe sobre a classificação dos corpos de água e diretrizes ambientais para o seu enquadramento, bem como estabelece as condições e padrões de lançamento de efluentes, e dá outras providências. Publicação DOU no 053, de 18/03/2005, págs. 58-63.

Lei no 9.433, de 8 de janeiro de 1997. Institui a Política Nacional de Recursos Hídricos, cria o Sistema Nacional de Gerenciamento de Recursos Hídricos, regulamenta o inciso XIX do art. 21 da Constituição Federal, e altera o art. $1^{\circ}$ da Lei $n^{\circ} 8.001$, de 13 de março de 1990, que modificou a Lei no 7.990, de 28 de dezembro de 1989.

Estudos Geográficos, Rio Claro, 17(1): 68-90, jan./jun. $2019 \quad$ (ISSN 1678-698X) http://www.periodicos.rc.biblioteca.unesp.br/index.php/estgeo 
CARVALHO, P.R.S. A expansão urbana na bacia do Ribeirão Mestre d'Armas (DF) e a qualidade da água. Estudos Geográficos, Rio Claro, v. 3, p. 71-91, 2005.

CARVALHO, K.Q.; LIMA, S.B.; PASSIG, F.H.; GUSMÃO, L.K.; SOUZA, D.C.; KREUTZ, C.; BELINI, A.D.; ARANTES, E.J. Influence of urban area on the water quality of the Campo River basin, Paraná State, Brazil. Brazilian Journal of Biology, v. 75, n. 4, pp. 96-106, 2015.

CONCEIÇÃO, F.T.; SANTOS, C.M.; SARDINHA, D.S.; NAVARRO, G.R.B.; GODOY, L.H. Chemical weathering rate, denudation rate, and atmospheric and soil $\mathrm{CO}_{2}$ consumption of Paraná flood basalts in São Paulo State, Brazil. Geomorphology, v. 233, pp. 41-51, 2015.

COSTA, D.A.T.; GUIÇARDI; A.C.F.; SARDINHA, D.S.; MINCATO, R.L. Qualidade ambiental de sub-bacia hidrográfica urbana: um estudo de caso de Alfenas - MG. Ciência e Natura, Santa Maria v. 40, e20, pp. 01-14, 2018.

CEMADEN. Centro Nacional de Monitoramento e Alerta de Desastres Naturais. Rede Observacional para Monitoramento de Risco de Desastres Naturais do Cemaden: Download de dados - dados pluviométricos. Disponível em http://www.cemaden.gov.br/mapainterativo/\#. Acesso em 02/12/2018.

CHUERUBIM, M. L.; PAVANIN, E. V. Análise do uso e ocupação do solo na bacia hidrográfica do Córrego Barbosa no ano de 2011. GEOUSP - Espaço e Tempo, São Paulo, n. 33, pp. 229- 238, 2013.

COSTA, D. A. T.; GUIÇARDI, A. C. F.; SARDINHA, D. S. S.; MINCATO, R. L. Qualidade ambiental de sub-bacia hidrográfica urbana: um estudo de caso de Alfenas - MG. Ciência e Natura, Santa Maria v. 40, e20, 2018.

CUNHA, S. B. Geomorfologia Fluvial. In: CUNHA, S. B.; GUERRA, A. J. T. Geomorfologia: exercícios, técnicas e aplicações. Editora Bertrand Brasil, $7^{\circ}$ ed., Rio de Janeiro, 2017, 345p.

ELLERT, R. Contribuição à geologia do maciço alcalino de Poços de Caldas. Boletim Faculdade de Filosofia, Ciências e Letras USP, São Paulo, v. 237, n. 18, p. 5-63, 1959.

FERNANDES, A.M.; CONCEIÇÃO, F.T.; JUNIOR, E.P.S.; SARDINHA, D.S.; MORTATTI, J. Chemical weathering rates and atmospheric/soil $\mathrm{CO}_{2}$ consumption of igneous and metamorphic rocks under tropical climate in southeastern Brazil. Chemical Geology, v. 443, pp. 54-66, 2016.

FILHO, E.A.F.; CHUI, Q.S.H. Qualidade de medições e neutralização de efluentes alcalinos com dióxido de carbono. Revista Engenharia Sanitária e Ambiental, v.11, ํo 2, pp. 169-174, 2006.

FUJIMOTO, N.S.V.M. Implicações ambientais na área metropolitana de Porto Alegre - RS: um estudo geográfico com ênfase na geomorfologia urbana. GEOUSP Espaço e Tempo, São Paulo, № 12, pp. 141-177, 2002.

Estudos Geográficos, Rio Claro, 17(1): 68-90, jan./jun. 2019 (ISSN 1678-698X) http://www.periodicos.rc.biblioteca.unesp.br/index.php/estgeo 
GOOGLE EARTH PRO. Imagens de satélite. Recuperado em 16 de setembro de 2018, de https://earth.google.com.

HERMES, L.C.; SILVA, A.S. Avaliação da qualidade das águas: manual prático. Brasília: Embrapa Informação Tecnológica, 2004, 55p.

HIRUMA, S. T.; PONÇANO, W. L. Densidade de drenagem e sua relação com fatores geomorfopedológicos na área do alto Rio Pardo, SP e MG. Revista IG. São Paulo, v. 15, pp. 49-57, 1994.

HOROWITZ, A.J. Monitoring suspended sediments and associated chemical constituents in urban environments: lessons from the city of Atlanta, Georgia, USA Water Quality Monitoring Program. Journal of Soils and Sediments, v. 9, pp. 342363, 2009.

IBGE. Instituto Brasileiro de Geografia e Estatística. Banco de dados: o Brasil município por município. Disponível em http://www.ibge.gov.br/cidades. Acesso em: 07 maio 2018.

Superintendência de Cartografia. Carta em escala 1:50.000. Poços de Caldas, Folha SP-23-V-C-VI-4. IBGE, 1972.

KOPPEN, W. Climatologia. México: Fondo de Cultura Econômica, 1948, 478p.

LUCAS, L., \& CUNHA, S. Rede de drenagem urbana em área tropical: mudanças na morfologia do canal e níveis de poluição das águas - Rio dos Macacos - Rio de Janeiro - RJ. GEOUSP: Espaço e Tempo (Online), (22), 39-64, 2007.

MACHADO, F. H.; DUPAS, F. A. Valoração de recursos hídricos como subsídio na gestão do manancial urbano do Ribeirão do Feijão, São Carlos - SP. GEOUSP Espaço e Tempo, São Paulo, №33, pp. 111- 126, 2013.

MENEZES, P.H.B.J.; ROIG, H.L.; ALMEDIA, T.; SOARES NETO, G.B.; ISAIAS, F.B. Análise da evolução do padrão de uso e ocupação do solo na bacia de contribuição do Lago Paranoá - DF. Estudos Geográficos, Rio Claro, v. 8, p. 88-106, 2010.

McGRANE, S.J. Impacts of urbanisation on hydrological and water quality dynamics, and urban water management: a review. Hydrological Sciences Journal - Journal des Sciences Hydrologiques, v. 61, n.13, pp. 2295-2311, 2016.

MORAES, F.T.; JIMÉNEZ-RUEDA, J.R. Fisiografia da região do planalto de Poços de Caldas, MG/SP. Revista Brasileira de Geociências, v. 38(1), 2008, p. 196-208.

MORAES, F.T.; JIMÉNEZ-RUEDA, J.R. Importância de estudos fisiográficos no planejamento municipal: exemplo do jardim botânico de Poços de Caldas, MG. Geociências, v. 24, n. 3, p. 255-266, 2005.

OLIVEIRA, A.M.S.; CAMPOS, D. C. A ocupação das várzeas no Alto Tietê e a reprodução deste modelo urbano na bacia do Rio Baquirivu Guaçu, Guarulhos e Arujá - SP. GEOUSP - Espaço e Tempo, São Paulo, №32, pp. 198-213, 2012.

Estudos Geográficos, Rio Claro, 17(1): 68-90, jan./jun. $2019 \quad$ (ISSN 1678-698X) http://www.periodicos.rc.biblioteca.unesp.br/index.php/estgeo 
OLIVEIRA, H.; MORTATTI, J. ; MORAES, G.M.; VENDRAMINI, D. ; CAMPOS, K. B. G. Caracterização hidrogeoquímica da carga dissolvida nas bacias dos Rios Jundiaí e Capivarí, São Paulo. Revista Geociências, v. 33, n. 2, p.278-297, 2014.

OLIVEIRA, D.G.; VARGAS, R.R.; SAAD, A.R.; ARRUDA, R.O.M.; DALMAS F. B.; AZEVEDO, F.D. Land use and its impacts on the water quality of the Cachoeirinha Invernada Watershed, Guarulhos (SP). Revista Ambiente \& Água, v. 13 n.1, e2131, pp. 01-17, 2018.

PMPC. Prefeitura Municipal de Poços de Caldas. Revisão do Plano Diretor. Poços de Caldas: Secretaria de Planejamento e Coordenação, 2006, 178 p.

PORTO, F.A., Estabelecimento dos parâmetros de controle da poluição. In: PORTO, S.M.; CLEARY, R. W. ; COIMBRA, R. M.; EIGER, S.; LUCA, S. J. ; NOGUEIRA, V. P. O.; PORTO, F. A. (eds), Hidrologia Ambiental. São Paulo, EDUSP, pp. 375-390, 1991.

RAPOSO, A. A.; BARROS, L. F. P; MAGALHÃES JÚNIOR, A. P. O parâmetro de turbidez das águas como indicador de impactos humanos na dinâmica fluvial da bacia do Rio Maracujá - Quadrilátero. In: XIII Simpósio Brasileiro de Geografia Física Aplicada, SBGFA, Viçosa, 2009. Trabalho completo disponível em: http://www.geomorfologia.ufv.br/simposio/simposio/trabalhos/trabalhos_completos/ei xo3/007.pdf. Acesso em 26/11/2018.

ROLDÃO, A.L.; SANTOS, J.G.; OLIVEIRA, L.A. Correlação entre as variáveis climáticas (altitude, temperatura e precipitação) na mesorregião Sul e Sudoeste de Minas Gerais - MG. Revista Geonorte, Edição Especial 2, v.1, n.5, pp.515-525, 2012.

SOUZA, A.D.G.; TUNDISI J.G. Water quality in watershed of the Jaboatão River (Pernambuco, Brazil): a case study. Brazilian Archives of Biology and Technology, $n^{\circ}$ 46, pp. 711-721, 2003.

SANTOS, J.M.; LIMA, K.C. Análise da rede de drenagem em bacias hidrográficas tropicais: bacia do Riacho Grande - Bahia/Brasil. Publicações da Associação Portuguesa de Geomorfólogos, v. 06, pp. 77-82, 2009.

STEVAUX, J.C.; LATRUBESSE, E.M. Geomorfologia Fluvial. Editora Oficina de Textos, $1^{\circ}$ ed., São Paulo, 2017, 336p.

STANDARD METHODS. Standard methods for the examination of water and wastewater. $20^{\circ}$ ed., American Public Health Association, Washington, 1999, 663p.

TINÓS, T.M.; FERREIRA, M.V.; RIEDEL, P.S.; ZAINE, J.E. Aplicação e avaliação de metodologia de classificação automática de padrões de formas semelhantes do relevo. Revista Brasileira de Geomorfologia, São Paulo, v.15, n.3, p.353-370, 2014.

Estudos Geográficos, Rio Claro, 17(1): 68-90, jan./jun. $2019 \quad$ (ISSN 1678-698X) http://www.periodicos.rc.biblioteca.unesp.br/index.php/estgeo 
VITTE, A.C.; MELLO, J.P. Mapeamento da fragilidade ambiental na bacia do Rio Verde, região Nordeste do Estado de São Paulo, Brasil. GEOUSP - Espaço e Tempo, São Paulo, № 35, p. 192-222, 2013.

VOM SPERLING, M. Introdução a qualidade das águas e ao tratamento de esgotos. $2^{\circ}$ ed. Belo Horizonte: Departamento de Engenharia Sanitária e Ambiental; Universidade Federal de Minas Gerais, 1996, 211p.

VOM SPERLING, M. Estudos e modelagem de qualidade da água de rios. $1^{\circ} \mathrm{ed}$. Belo Horizonte: Departamento de Engenharia Sanitária e Ambiental; Universidade Federal de Minas Gerais, 2007, 588p.

ZAINE, J.E.; CERRI, L. E. S.; SCALVI, H. A.; MANZANO, J. C.; POCAY, W. R. H.; HIRATA, M. T.; SANTANA, G. C. P.; TINÓS, T. M. Estudo de caracterização geológico geotécnica aplicado ao planejamento rural e urbano do município de Poços de Caldas, MG. Rio Claro, SP: Fundação de Apoio à Pesquisa, Ensino e Extensão - FUNEP, 54p. , 2008.

\section{Agradecimentos}

Os autores agradecem o apoio financeiro concedido pela Pró-Reitoria de Pesquisa e Pós-Graduação (PRPPG) da Universidade Federal de Alfenas (Unifal). Os autores também agradecem aos revisores anônimos que contribuíram com a melhora deste manuscrito. 